PAPERS IN PHYSICAL OCEANOGRAPHY AND METEOROLOGY

$$
\text { Published by }
$$

MASSACHUSETTS INSTITUTE OF TECHNOLOGY

AND

WOODS HOLE OCEANOGRAPHIC INSTITUTION

$$
\text { VOL. VI, NO. } 4
$$

\title{
ON THE MEASUREMENT OF DROP SIZE AND LIQUID WATER CONTENT IN FOGS AND CLOUDS
}

BY

H. G. HOUGHTON AND W. H. RADFORD

CAMBRIDGE AND WOODS HOLE, MASSACHUSETTS

November, 1938 


\begin{abstract}
I. A short critical review of possible methods for the measurement of the size of fog particles is presented. It is concluded that the only suitable method of obtaining the distribution of drop sizes present in a given fog consists in the microscopic measurement of large numbers of drops which have been collected on a properly surfaced slide. A method for surfacing microscope slides with a thin, uniform layer of petroleum grease is described. The important problem of obtaining a representative sample of drops on a slide is next considered. Experimental results indicate that slides no larger than $5 \mathrm{~mm}$ square will collect satisfactory samples if exposed facing the wind. Larger slides are found to discriminate against the smaller drops. Special fog microscopes which have been constructed for observing droplet samples are described, and typical results obtained in natural fogs are presented. Although forty sets of data have been procured in sixteen different fogs, it has not been possible to correlate the drop size data with any of the accompanying meteorological conditions. There is no evidence of mass grouping, such as Köhler observed in clouds; however, definite conclusions cannot be drawn from such a relatively small amount of data.

II. The usefulness of fog water data is indicated and possible methods of procuring them are reviewed. An investigation of the sampling problem encountered in the operation of most fog measuring instruments is described. The method of avoiding sampling difficulties in a new fog water instrument is explained and the constructional features and operation of the apparatus are
discussed.

The essential part of the new instrument is a unit comprising a succession of ordinary wire screens through which a motor driven fan forces foggy air at a measured rate. The central portion of this screen unit is removable for weighing. Liquid water determinations are made from the weight increments of this unit corresponding to the passage through it of a known volume of air as indicated by a vane anemometer. The outer section of the screen unit serves as a guard ring for the central measuring unit, thereby avoiding sampling errors, and at the same time functions as the collector of samples of fog water for chemical analysis.

From the results of numerous measurements it has been determined that in the typical advection fogs which occur at Round Hill the liquid water content may range up to approximately $0.25 \mathrm{~g} / \mathrm{m}^{3}$. Total dissolved salt contents of from 8 to $480 \mathrm{mg} / \mathrm{l}$ have been observed. The number of drops per cc of foggy air has been found to be usually less than five.
\end{abstract}




\title{
I. MICROSCOPIC MEASUREMENT OF THE SIZE OF NATURAL FOG PARTICLES*
}

\author{
BY \\ H. G. HOUGHTON† AND W. H. RADFORD \\ Round Hill Research Division, Department of Electrical Engineering \\ Massachusetts Institute of Technology
}

The size distribution of the particles comprising a fog is one of its most significant physical characteristics. Knowledge of the size distribution is important in the theoretical treatment of problems relating to visibility and the transmission of radiant energy through fog. Recently the size of fog particles has been of interest in connection with the development and application of a method for the local dissipation of fog. ${ }^{1}$ Data on particle size as well as on all other significant physical properties of fog are of considerable meteorological importance insofar as they contribute to a better understanding of fog structure and the processes of fog formation.

A paper published by one of the authors in $1932^{2}$ described the development of a method for the microscopic measurement of natural fog particles. The particles were collected on a grease-coated glass slide and were measured either visually, with the aid of an eyepiece micrometer, or by the subsequent measurement of photomicrographs. Typical particle size distribution curves obtained in natural fog were presented and some tentative conclusions were drawn. The development of this method has continued since that time and it is the purpose of the present paper to describe the improved apparatus and technic and to present typical examples of the results which have been obtained. A brief review of the general problem of the determination of fog and cloud particle sizes is also included.

\section{Available Methods of Size Measurement}

Various methods of fog and cloud particle measurement have been employed by different observers. Probably the best known is the corona method which has been used extensively by Köhler ${ }^{3}$ and also by Barus, ${ }^{4}$ Wagner, $^{5}$ Mecke, ${ }^{6}$ Werner, ${ }^{7}$ Hartmann, ${ }^{8}$ Richardson, ${ }^{9}$ and others. This method is based on the optical theory of the coronal rings observed around light sources viewed through fog or cloud. As usually applied, it yields only an average or predominant particle size. For the solution of most problems concerning fog it is necessary to know not only the predominant size but also the actual range and distribution of the drop diameters. Numerous attempts have been made to

\footnotetext{
* Although the research reported here was begun as part of a light scattering investigation, it was continued also as a phase of the Fog Dissipation project supported in part by a grant from the Penrose Fund of the American Philosophical Society and through joint contracts with the Bureau of Aeronautics of the U. S. Navy Department, the U. S. Army Air Corps, and the Bureau of Air Commerce of the U. S. Department of Commerce covering several years.

The work was carried out at the Institute laboratories on the Round Hill estate of the late Colonel E.H. R. Green whose foresight and generosity made the project possible. Not only did Colonel Green offer the natural facilities of his estate to the Institute for use as a laboratory, but he also aided by numerous gifts, financial and otherwise. Through the courtesy of Mrs. H. Sylvia A. H. G. Wilks, sister of Colonel Green, we have been enabled to continue work at Round Hill so as to complete our projects.

Round Hill is at South Dartmouth, Massachusetts, on the west shore of Buzzards Bay, about six miles south of the city of New Bedford.

$\dagger$ Now in Meteorological Division. Department of Aeronautical Enginecring, Massachusetts Institute of Technology.
} 
apply the corona method to Round Hill fogs but the results have been uniformly unsatisfactory, presumably because of the rather wide range of drop sizes always present. Apparently the corona method is suitable only for fogs or clouds comprising particles of a very uniform size. It is interesting to note that in a recent theoretical study of optical methods of measuring small water drops, Wilson ${ }^{10}$ concludes that the corona method is not applicable to drops smaller than about 20 microns in diameter and further states that there is no reliable optical method for drops having diameters between about 3 and 20 microns.

Another possible procedure of size measurement is the sedimentation method whereby, in general, the particle sizes are determined with the aid of Stokes' law from observed rates of settling under gravitational or electrical forces. This method is simple in theory but difficult in practice and does not seem to be well suited to measurements in natural fog because of the inherent difficulties of avoiding errors resulting from evaporation of the droplets during the sedimentation period. Adaptations of this method have been used in artificial fogs by Fuchs and Petrianow ${ }^{11}$ and also by Heubner ${ }^{12}$ and by Rohmann. ${ }^{13}$

A third possible means of determining fog particle sizes is by direct photography of the individual drops contained in a small volume of foggy air. Although some preliminary development work has been done on it at this laboratory, so far as is known, the method has not yet been successfully applied to natural fog. The method purposes to illuminate only those drops which are in focus, by employing a very thin transverse sheet of light. To obtain photographs of the normally rapidly moving drops it would be necessary to use as a light source an electric spark of high speed and intensity. The illuminated volume would be so restricted by any optical system having sufficient resolving power that it has been estimated that only about one drop would be photographed per exposure. Because of this, and other difficulties inherent in the design of the apparatus, further development of the method has been deferred.

Findeisen ${ }^{14}$ has employed a somewhat indirect photographic method of measuring fog particles in their natural state. He used low magnifications ( $I$ to 5 diameters) and shutter speeds of $\mathrm{I} / 2000 \mathrm{sec}$ with an arc light source. He made no attempt either to resolve individual drops or to have the photographed drops in focus, but simply obtained photographs of the diffraction rings produced by the drops. From the size and density of these images he was able to deduce the size of the fog drops by a somewhat intricate method. It is interesting to note that the distribution curves which he obtained all show a predominance of particles less than 5 microns in diameter and that many of them have no maxima.

It appears that the only other method of fog particle size determination of impor tance is the microscopic method described in the previous paper by one of the authors. ${ }^{2}$ Variations of this method have been used independently by a number of observers working with both natural and artificial fogs. In conjunction with his corona measurements Köhler ${ }^{15}$ made a few microscopic measurements of frozen drops and of liquid drops which he caught on fine wires. Haüsser and Strobl ${ }^{16}$ made measurements of atomized droplets which they collected on slides covered with a thin layer of oil. Heubner ${ }^{12}$ measured drop sizes of sprayed liquids using unsurfaced slides and observing both the height and diameter of the drops on the slide. Kinoshita and Uchiyama ${ }^{17}$ measured the size of artificial fog particles which they forced into a film of oil. They made interesting corrections for the rate at which the droplets evaporated in to the oil. More recently Hage- 
mann ${ }^{18}$ applied a similar method to natural fog drops and obtained about 67 size distribution curves having peaks ranging from 9 to 24 microns particle diameter. Fuchs ${ }^{19}$ and Petrjanoff ${ }^{2 n}$ have made microscopic measurements of fog and rain drops which were collected on slides covered with a mixture of vaseline and light mineral oil. They found natural fog particles ranging in size from $\mathrm{I} 2$ to 60 microns diameter.

The use of an oil layer on the slide to envelop the impinging drops has certain advantages over the use of a thin vaseline layer such as is described in this paper. If the oil is properly saturated with water the evaporation of the drops can be prevented, even when the slide is brought indoors, and if the proper oil mixture is used the drops will retain their spherical shape. However, the oil composition must be varied to suit the prevailing temperature, and also the oil tends to flow to the bottom of the slide when the slide is exposed in the vertical position (which the authors have found to be desirable). From published photomicrographs of drops in an oil film ${ }^{19}$ it appeared that the photographic contrast was very poor, especially in the case of the smaller drops, but preliminary investigations at this laboratory have indicated that satisfactory contrast can be obtained if a proper dark field illuminator is used. It is apparent from the photomicrographs which appear in this paper that excellent contrast is obtained when the drops rest on a greased surface.

Since the fog microscopes here described are always used out in the fog the evaporation problem is of no great importance. Normally, no evaporation is observed during periods very much longer than are required for taking the photomicrographs. Also, when a flattened drop partially evaporates its apparent diameter as observed from above usually does not change. It is often possible to determine the original diameter after the complete evaporation of the drop simply by observing the ring which remains on the greased surface. The flattening of the drops on the slide is a disadvantage, since a correction factor must be applied to obtain the original drop diameter, but errors due to variations in this factor, with the present technic, are now less than those from other causes. It may be concluded that both the oil and grease methods of slide surfacing have definite advantages and that the choice of the one or the other should depend on the requirements of the individual problem.

\section{Slide Surfacing}

Proper surfacing of the slides used for the collection of the fog drops is of the utmost importance. When fog drops rest on a horizontal surface they are more or less flattened by their own weight, the extent of the flattening depending upon the contact angle between the drop and the slide surface. On the basis of capillary theory it may be shown that the free surface of such a flattened drop is approximately spherical for drops smaller than about I mm diameter. Thus if the contact angle is known it is possible to determine the original diameter of the drop from its apparent diameter on the slide. For a given contact angle the ratio between the true diameter and the observed diameter is a constant which is independent of the drop size. The contact angle must be maintained constant over the entire slide surface and this may be accomplished by completely covering the glass surface with a uniform layer of clean grease. The surface must be smooth to avoid distortion of the drops and to provide a suitable background against which their outlines will be sharply defined.

The original method of slide surfacing consisted simply in wiping a thin film of petroleum grease (white vaseline) on the surface of a clean slide. The surface so formed, 
when viewed under dark field illumination, was found to be streaky and irregular so that some of the drops were always distorted and the contrast was poor. Subsequently, the technic of slide surfacing was improved resulting in the production of much more uniformly surfaced slides. The improved method finally selected after considerable experimentation consists in spreading a moderately heavy coating of vaseline on the surface of a perfectly clean slide and then placing the slide in a vertical position in an oven at a temperature of $300^{\circ} \mathrm{F}$ for three minutes. It is absolutely essential that the slide surface be clean before the grease is applied as otherwise the grease may collect in spots instead of spreading uniformly. It has been found that the slides can be adequately cleaned by first scouring them with concentrated chromic acid, then thoroughly rinsing them in distilled water and finally allowing them to dry in a dust free atmosphere. Slide surfaces carefully prepared in this manner are so uniform that they are practically invisible when viewed with intense dark field illumination. The degree of uniformity of slide surfacing by the improved method is such that flattening variations cause no more than a $5 \%$ error in the determination of the original drop diameters from the observed diameters of the flattened drops.

Determinations of the coefficient by which the diameters of the flattened drops must be multiplied to obtain the original drop diameters have been made by two methods. One method involved the measurement of the height and diameter of individual flattened drops, which were viewed from the side. The "flattening coefficient" could then readily be computed. In the second method an average value of the flattening coefficient was obtained by determining the total weight of a number of flattened drops resting on a slide and then measuring the diameters of the individual drops. Rather large drops were used for most of these measurements in order to obtain convenient weights, but in one case this procedure was applied to natural fog particles and a result was obtained which was in close agreement with the results of the other determinations of the flattening coefficient. From numerous measurements it has been found that the flattening coefficient for water drops resting on a vaseline surface is $0.80 \pm 0.04$.

\section{The Sampling Problem}

In order to obtain the true drop size distribution of a fog or cloud it is evidently desirable to collect a representative sample of the drops on the slide, or if the sample is not truly representative the law governing the departure should be known. A proper sample will be obtained if all of the droplets from a given volume of foggy air are deposited on the slide. Theoretically this might be accomplished by isolating a portion of the foggy air in a tube and allowing all of the drops to settle on to a slide located at the bottom, as suggested by Fuchs and Petrjanoff. ${ }^{20}$ However, such a procedure is impractical because, in the considerable time required for all of the particles to settle, the ambient conditions can easily change enough to greatly modify the size of the drops. Also, the isolation of a true sample of the foggy air would be extremely difficult, particularly if there were an appreciable wind.

It has been our practice to expose the slides either horizontally in the fog microscope slide holder or vertically facing the wind. When the wind velocity is very low it has been found necessary to move the slide broadside through the foggy air. On numerous occasions when fog conditions were quite stable, successive slides were exposed horizontally in the microscope slide holder and facing the wind vertically. The samples obtained by the two methods of exposure were found to be identical within the limits of accuracy of 
the measurements. Tests made in calm foggy air indicated that a sample obtained by moving a slide through the air at about $\mathrm{I} \mathrm{m} / \mathrm{sec}$ was substantially the same as one secured at a velocity of about $20 \mathrm{~m} / \mathrm{sec}$.

Hagemann ${ }^{18}$ obtained his samples by placing slides behind the small end of a tapered opening through which the foggy air was drawn at a velocity of about $15 \mathrm{~m} / \mathrm{sec}$. A similar arrangement was tried at this laboratory and slides so exposed were compared with slides exposed facing the wind. It was found that there were fewer large drops on the slides exposed in the model of Hagemann's apparatus than on those exposed facing the wind. Because of their greater kinetic energy some of the larger drops were evidently deposited on the walls of the tapered opening and it was concluded, therefore, that this is not a suitable method for obtaining a true sample of the fog particles.

In another attempt to learn something of the manner in which the drops are deposited on a slide the total volume of the drops collected on a slide held facing the wind was determined. This quantity was then compared with the total amount of liquid water contained in the foggy air which would have passed through the area occupied by the slide surface during the time of exposure. (This latter value was computed from the average wind velocity normal to the slide and the liquid water content of the fog as measured by a "fog separator."*) It was found that the two quantities were nearly equal indicating that the drops which comprise the bulk of the liquid water were deposited on the slide. The results of this experiment suggest the use of this method of slide exposure to determine the number of fog drops in a unit volume of foggy air, as well as their size.

Notwithstanding the results of the investigations described above it has been suspected for some time that a truly representative sample is ordinarily not obtained. Because of the great difference in kinetic energy between the large and the small drops there is reason to believe that the small drops may be discriminated against. This question can be properly settled only by making a comparison with samples obtained by a method of known reliability, such as the sedimentation method mentioned above. The practical difficulties which preclude the application of this method to natural fog have been pointed out. It was decided, therefore, to make the comparison in an artificial fog formed by atomizing a salt solution of such concentration that the droplets would be in size equilibrium with the surrounding atmosphere. Artificial fog was introduced into a vertical pipe of $10 \mathrm{~cm}$ diameter through which an appropriate air flow could be maintained. A short section of the pipe was equipped with shutters so that a portion of the foggy air could be isolated to allow the drops to sediment onto a slide. Sedimentation samples so obtained were compared with impact samples collected by introducing a slide faced normal to the air flow.

As anticipated, it was found that the sedimentation samples comprised a much greater proportion of small drops than the impact samples. However, the method by which the sedimentation samples were obtained is not considered very satisfactory because of the turbulence induced by the closing of the shutters. This factor probably caused some of the larger drops to be deposited on the wall of the pipe. For this reason the results should probably be regarded only as qualitative. Nevertheless, it was quite definitely established that the method which heretofore has been used for the collection of samples of natural fog particles discriminates against particles smaller than about 20 microns in diameter. Since this effect becomes more pronounced as the drop size is reduced, an almost negligible proportion of the drops smaller than 5 microns is collected. Prac-

* See Part II. 
tically all of the liquid water contained in the fogs which have been observed at Round Hill is in the form of drops having diameters greater than 20 microns so that the data presented in this paper are not subject to much modification as a result of the findings just outlined. However, it is planned to develop a better method of obtaining sedimentation samples in artificial fog so that quantitative correction factors can be determined which may be applied to the size data procured from impact samples of natural fog particles on slides $25 \mathrm{~mm}$ square.

The application of correction factors to take care of the sampling difficulty is not entirely satisfactory, particularly in the case of fogs having a predominant particle diameter less than 20 microns, and a means for obtaining a more representative sample has therefore been sought. From a simplified analysis of the factors influencing the deposition of the droplets on the slide, which include the kinetic energy of the drops, the resisting force when the drops deviate from the streamlines and the nature of the velocity field in front of the slide, it was decided that a smaller slide may be expected to collect more of the smaller drops. Accordingly, $5 \mathrm{~mm}$ square slides were substituted for the standard $25 \mathrm{~mm}$ square slides and, using the same artificial fog apparatus described above, samples for comparison were collected by impact and by sedimentation. Again the results could not be considered to be quantitative, but it appeared that representative samples were obtained on the small slides exposed by impact for drops down to about 5 microns in diameter. It was definitely demonstrated that the $5 \mathrm{~mm}$ slides obtained a much truer sample of the fog than did the $25 \mathrm{~mm}$ slides. The use of the small slides is therefore indicated in all cases where drops less than about 20 microns in diameter are of importance.

\section{The Improved Fog Microscopes}

Since the publication of the paper already referred to describing the first fog microscope constructed at Round Hill, two greatly improved models have been built. The first of these, which was constructed in the fall of 1935 , has been used extensively for routine observations in fog and also for numerous measurements of the sizes of drops formed by spray nozzles. The other improved microscope, constructed in the spring of 1936, has been used satisfactorily in the field for over a year by another observer.* Due to improvements in their optical and mechanical features, and the use of better surfaced slides, the new instruments yield photomicrographs which are vastly superior to those obtained with the original apparatus. To prevent the evaporation of the fog drops while they are being measured, the microscopes have been designed to be used out in the fog. They are much more compact than the original instrument and are also more convenient to operate because of the simple external controls which are provided. Standard incandescent lamps are used which may be operated either from a single storage battery or other convenient source. With the new microscope, it is readily possible to obtain several photomicrographs within a minute.

Fig. I is a photograph of the microscope which was constructed in I935. This instrument utilizes a simple system of bright field illumination including a water cell which reduces to a minimum the amount of radiant heat reaching the slide. This model is arranged primarily for photographic observation and is equipped with a $16 \mathrm{~mm}$ Micro-Tessar lens giving a magnification of $25.4 \times$. The standard $9 \times 12 \mathrm{~cm}$ film pack holder and a

* Mr. Alan C. Bemis has generously cooperated with us in obtaining data in fogs and clouds at various locations. It is expected that some results of this work will be published in the near future. 
ground glass and hood are mounted on a sliding carriage to facilitate focusing. A convenient toggle-type shutter automatically gives the proper film exposure. The slide holder is constructed so that any desired portion of the slide surface can be observed.

Fig. 2 is a photograph of the later and somewhat improved model. This instrument employs dark field illumination and is equipped with a $16 \mathrm{~mm}$, Io $\times$ microscope objective mounted in a microscope tube of standard dimensions. Any of a number of oculars may

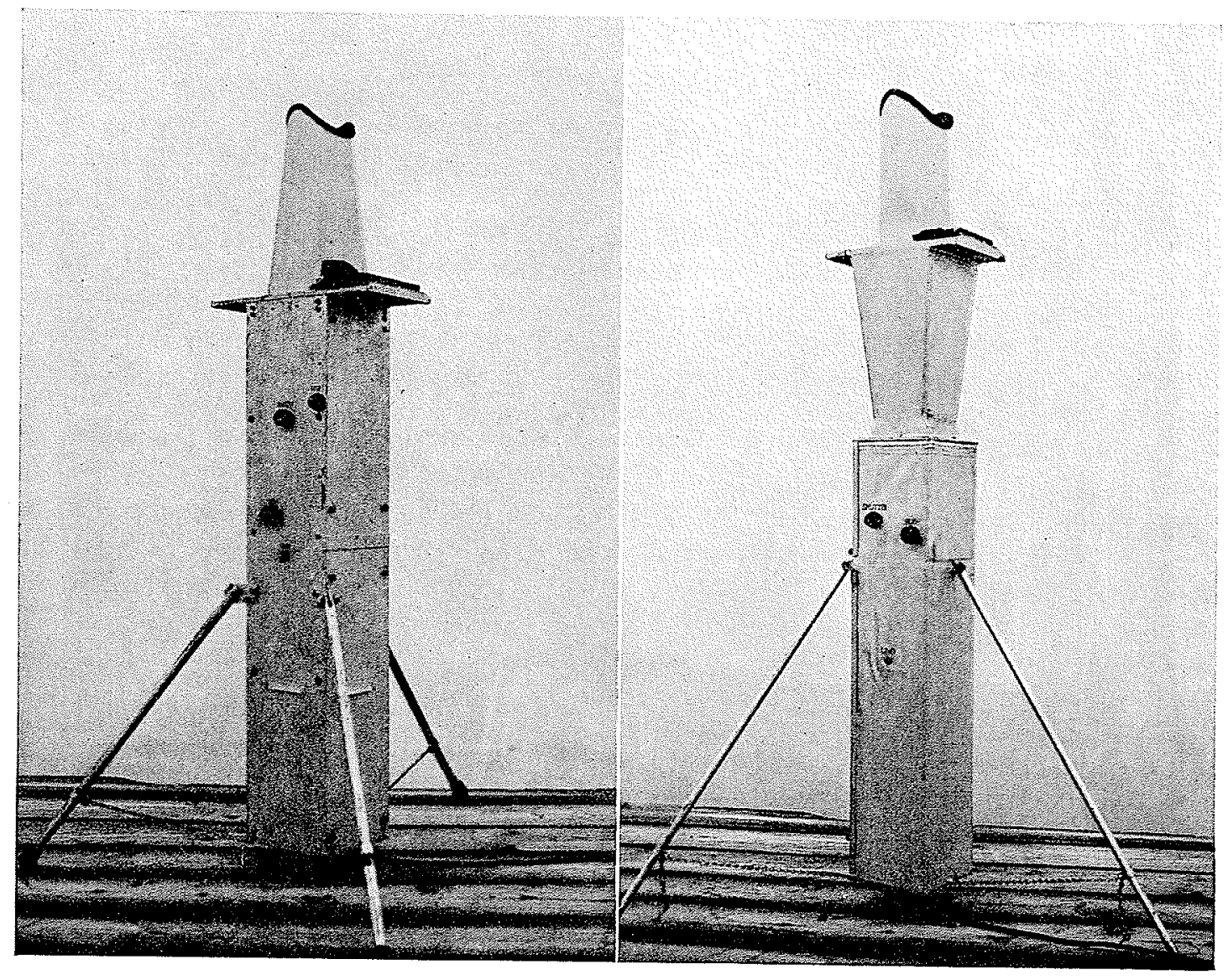

FIG. I.-The 1935 model of the fog microscope. This instrument has bright field illumination and is equipped for photographic use. Three of the four control knobs can be seen in the illustration. The framework of the instrument is of angle iron and the covering is of sheet metal. One side is removable to provide easy access to the interior.

Frg. 2. - The I 936 model of the fog microscope. This instrument uses dark field illumination and is equipped with standard microscope optics. The upper portion of the instrument, comprising the samera, is removable. The framework is of welded steel tubing and the covering is of fabric and sheet metal.

be used, depending on the overall magnification desired, about $80 \times$ usually being employed for photographic observations. The upper portion of the instrument, which comprises the camera, is removable so that this microscope can also be used for direct visual measurements. Other essential features of this instrument are similar to those of the bright field microscope described above.

Considerable experience with these two fog microscopes has revealed the superiority of the dark field model. With bright field illumination the contrast is very poor for the 
smaller fog drops, whereas even dust and smoke particles are readily visible under dark field illumination. It is also generally desirable to use a higher magnification than can be obtained with a single projection-type lens working at a reasonable image distance. It

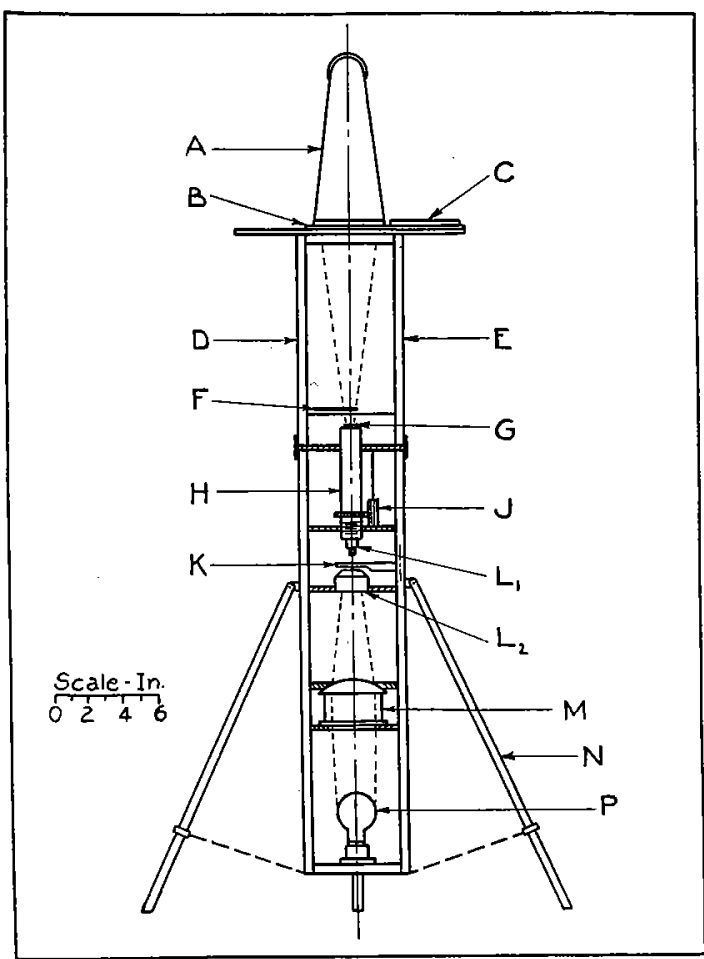

Fig. 3.-Diagram of an improved fog microscope incorporating all of the features which experience with the older instruments has shown to be desirable.

A. Removable hood over ground glass to facilitate focusing.

B. Sliding carriage bearing ground glass and film pack.

C. Standard $9 \times 12 \mathrm{~cm}$ film pack holder.

D. Framework of light angle stock. Light-tight covering preferably of sheet metal with two removable sides.

E. Upper section comprising camera removable to permit direct visual observations.

F. Automatic mechanical shutter.

G. Standard eyepiece (about $6 \times$ ).

$H$. Tube for standard microscope optics.

J. Focusing mechanism.

$\mathrm{K}$. Slide holder mounted so it can be swung out into fog.

L. Standard $16 \mathrm{~mm}$ (IOX) objective.

L2. Standard condenser preferably for dark field illumination.

M. Combined water cell and condenser.

N. Adjustable leg.

P. Standard incandescent lamp.

has also been found convenient to have the instrument arranged so that visual observations can be made. Recently, specifications have been prepared for a new fog microscope incorporating the desirable features of the present dark field model together with certain 
additional improvements. The general arrangement of the proposed instrument is shown in Fig. 3 .

\section{Results of Observations in Fog}

When observations are made the fog microscope is used out in the fog, as already stated. Samples of fog particles are obtained by exposing the specially prepared microscope slides to the foggy air, usually by holding them vertically, faced in to the wind. When a sample has been collected the slide is placed immediately in the microscope slide holder to be observed and photographed. Photomicrographs of a number of different portions of each slide are usually taken in order to provide ample data. In exposing the surfaced slides to the foggy air care must be exercised to prevent the collection of an excessive number of drops. If too many drops are caught, coalescence is likely to occur. The length of exposure required for the collection of an adequate sample depends on the wind velocity and the fog density, and may vary from a few seconds to several minutes. With a little experience one has no difficulty in obtaining proper slide coverage. The concentration of drops on a slide should not, in general, exceed that indicated by the typical photomicrographs reproduced as Figs. 4, 5, and 6.*

The desired data on the size of fog particles are obtained from the photomicrograph negatives with the aid of a projection enlarger of conventional form. By means of this apparatus images of the negatives are projected upon a ground glass screen with a magnification of IOX or less. The enlarged images of the individual drops are then measured to the nearest whole division of a conveniently graduated scale. The overall magnification of the drop images, including the effect of flattening on the slide, is about $320 \times$ with

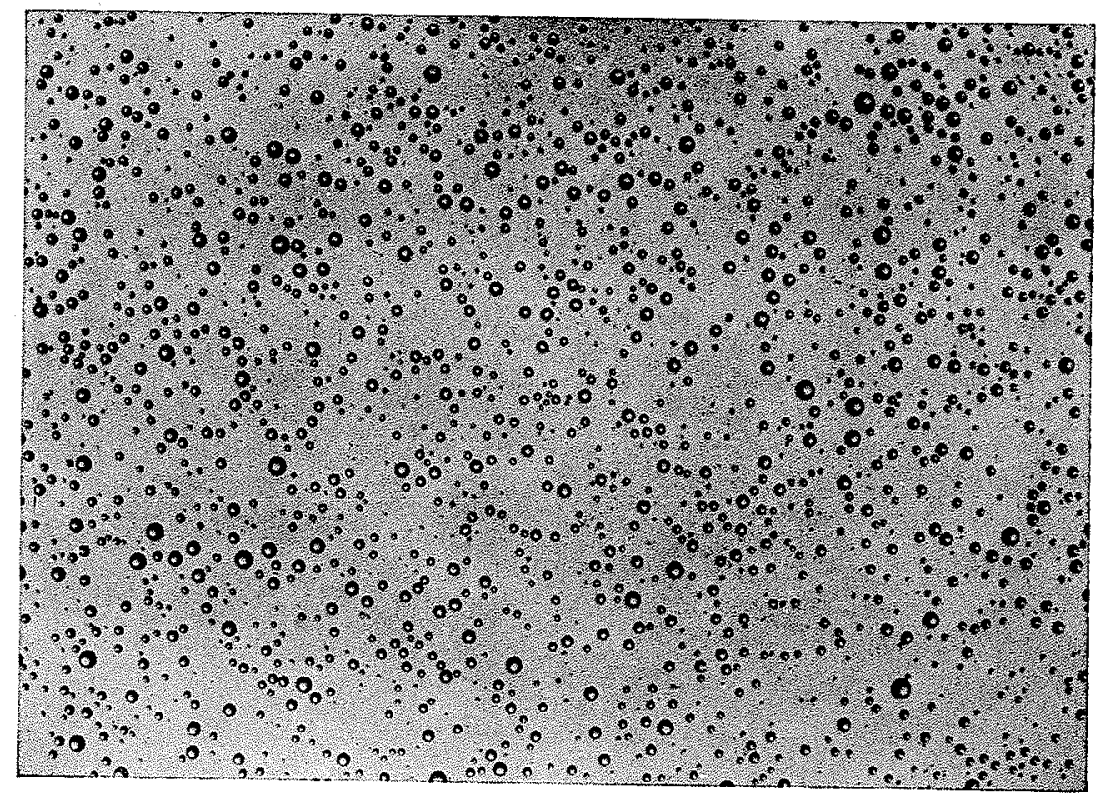

FIG. 4.-Photomicrograph of natural fog particles obtained with the instrument shown in Fig. I. Fog at Round Hill on Feb. I7, I936. The magnification of the drops as they are here reproduced (including flattening effect) is about $32 \times$. scopes.

* The photomicrographs reproduced in Figs. 4, 5, and 6 are the same size as the negatives obtained from the micro- 


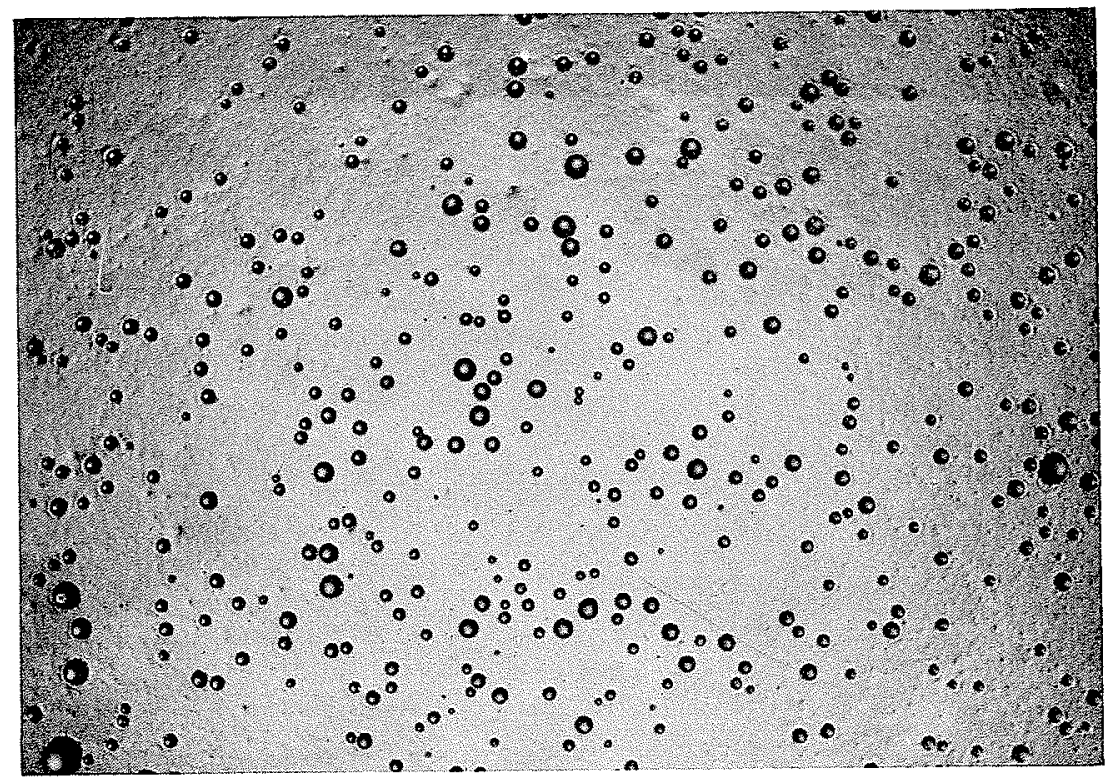

Fic. 5-Photomicrograph of natural fog particles obtained with the instrument shown in Fig. I. Fog at Round Hill on May 3, 1936. The magnification of the"drops as they are here reproduced (including flattening effect) is about $32 \times$.
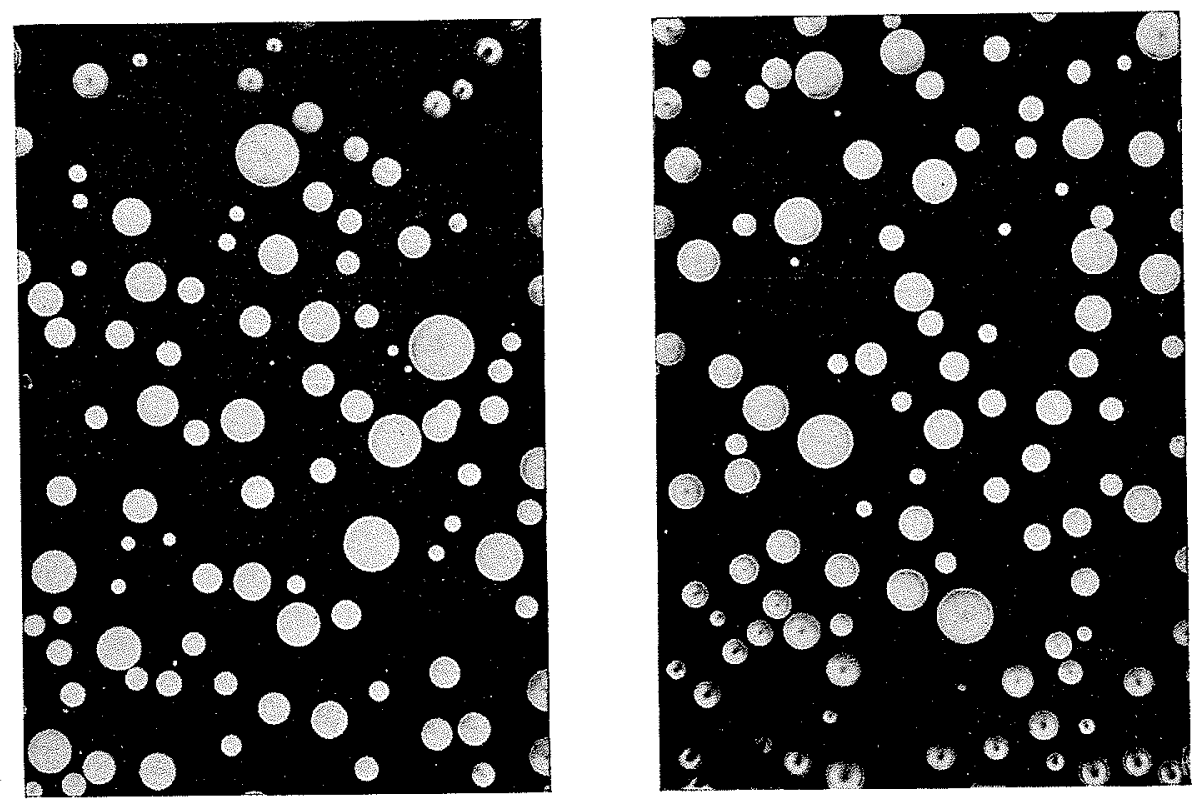

FIG. 6.-Photomicrographs of natural fog particles obtained with the dark field microscope shown in Fig. 2. Fog at Round Hill on Jan. 14, 1937. The magnification of the drops as they are here reproduced (including flattening effect) is about $70 X$. 
negatives from the bright field microscope (Fig. I) and $690 \times$ with negatives from the dark field instrument (Fig. 2). The accuracy with which the drop diameters can be measured is limited by the resolving power of the microscope and the graininess of the film. In measuring the drops the smallest scale division ordinarily used represents 2 or 3 microns.

The results of the fog particle size measurements have been found to be most useful when plotted as in Figs. 7, 8, and 9, which are the so-called volume distribution curves of the fog samples represented by the photomicrographs shown in Figs. 4, 5, and 6. These curves give the quantity $k n d^{3}$ as a function of $d$, where $k$ is an arbitrary constant and $n$

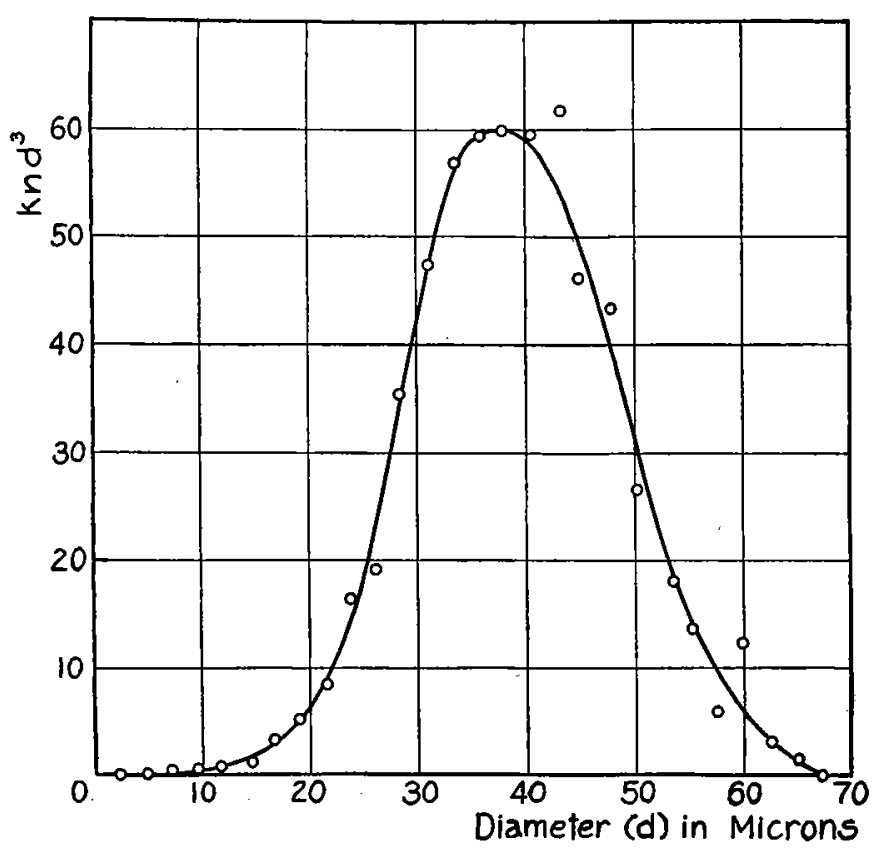

FIG: 7.-Volume distribution curve for the fog sample represented by the drops shown in Fig. 4. 1621 drops were measured to obtain data for this curve. The peak of the curve is near 38 microns. About $4 \mathrm{r} \%$ of the total liquid water is contained in drops falling within a ten micron band centered about the peak diameter.

is the relative number of particles of diameter $d$ in a given volume of foggy air. The curves therefore show the distribution of the liquid water among the particle sizes present in the fog.

The number of drops which must be measured to give a smooth curve depends on the width of the size groups selected for classifying the drops. Usually, with size groups about 5 microns wide, from 500 to Iooo drops must be measured to yield data sufficient for a good curve. With a proper number of drops on the slide, ordinarily less than 500 drop images are obtained on a single negative with the bright field microscope, and less than 100 with the dark field microscope.

The photomicrographs and distribution curves reproduced in the accompanying figures are typical of the many obtained from observations in natural fogs which have occurred at Round Hill during the past few years. All of these observations were made with the two improved microscopes described above. Virtually all of the fogs were either 


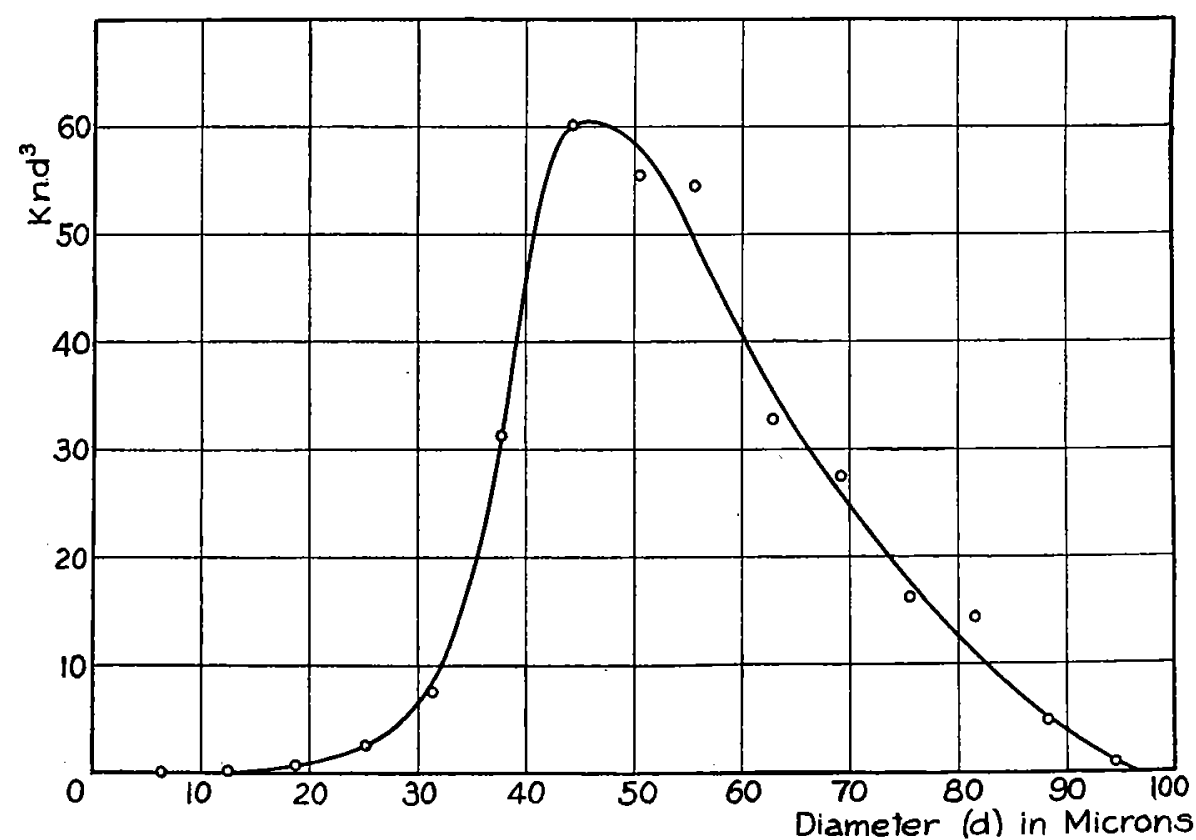

Fic. 8.-Volume distribution curve for the fog sample represented by the drops shown in Fig. 5. 750 drops were measured to obtain data for this curve. The peak of the curve is near 46 microns. Approximately $30 \%$ of the total liquid water is contained in drops falling within a ten micron band centered about the peak diameter.

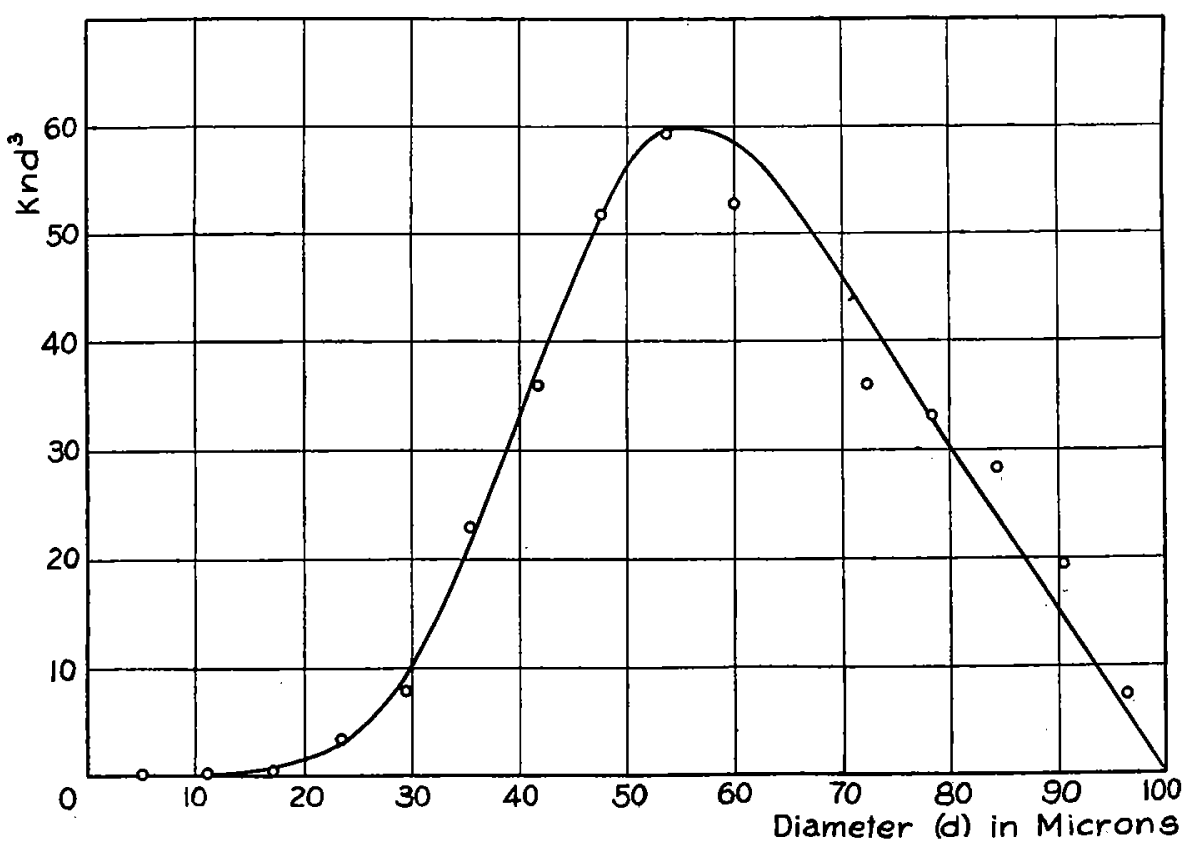

Fig. 9.-Volume distribution curve for the fog sample represented by the drops shown in Fig. 6. Only 345 drops were measured to obtain data for this curve. The peak of the curve is at about 55 microns. Approximately $23 \%$ of the total liquid water is contained in drops falling within a ten micron band centered about the peak diameter. 
frontal fogs or advection fogs of the tropical air mass or sea fog type. A total of forty curves was obtained, in 16 fogs, during a two-year period ending in January, 1 937. These fogs occurred in all seasons; temperatures ranged from $\mathrm{I}$ to $2 \mathrm{I}^{\circ} \mathrm{C}$, wind velocities from calm to $10 \mathrm{~m} / \mathrm{sec}$ and horizontal visibilities from 100 to $800 \mathrm{~m}$. The observed fog particle diameters ranged from 2 to I 30 microns. Each set of data obtained determined a smooth volume distribution curve having a single maximum and the general shape indicated by Figs. 7, 8 and 9. On a number of occasions photomicrographs were made of several samples of fog collected within a short time interval. The distribution curves obtained from the different sets of data were found to be practically identical showing the high degree of reproducibility of the measurements. It has also been observed that the shape and the location of the distribution curves do not change rapidly during a given fog, and of ten remain practically the same over a period of several hours.

The maxima of the forty volume distribution curves studied occur at particle diameters ranging from 12 to 90 microns, with a marked predominance between 40 and 50 microns. The curves differ somewhat in sharpness and they have been compared in this respect by determining the percentage of the total liquid water represented by the drops falling within a Io micron band centered about the peak of the curve. On this basis it is found that the "sharpness" ranges from I6 to $47 \%$, the most common value being about $30 \%$. Most of the curves are of such shape that more of the water is contained in drops larger than the peak diameter than in those smaller than the peak diameter. It has not been found possible to correlate any of the curve characteristics which have been described above with any of the meteorological conditions accompanying the fog. If any such correlation exists it will evidently be apparent only after considerably more data have been assembled.

In the earlier paper on fog particle size measurements by one of the authors, ${ }^{2}$ results were presented in the form of "size distribution curves" showing, for a given sample of fog, the relative frequency of drops of each diameter. With one exception, all of the size distribution curves which had been obtained at that time appeared to have definite peaks at diameters corresponding to integral multiples of 6.2 microns, the more common peak diameters being $6.2,12.4$, and 18.6 microns. It was poin ted out that this integral relationship might have a bearing on the process of fog formation but because of insufficient data no definite conclusions could be drawn. No such relationship is evident among the numerous sets of size measurements which have been made since with the improved fog microscopes. As the newer determinations are both more numerous and more accurate, it must be concluded that the relationship apparently existing among the earlier data was quite accidental, and without significance so far as the fog itself was concerned.

The diameters corresponding to the maxima of the volume distribution curves have been examined for evidence of the mass grouping phenomenon observed by Köhler ${ }^{3}$ in the results of his corona measurements in clouds. If a similar grouping exists in our data it is not apparent. The presence or absence of such grouping, however, cannot be definitely established until many more observations have been made.

In the course of the analysis of our results the usual corona theory ${ }^{21}$ was applied to two typical sets of Round Hill size data, one of which is represented by Fig. 7. In each case calculations were made to determine the angular radius of the first order coronal minimum. It was found that as a result of the wide range of particle diameters present no minima of practical significance exist. This result is well supported by experimental evidence. As noted previously in connection with the general discussion of methods of particle size determination, attempts to make corona measurements in Round Hill fogs 
have always been unsuccessful, usually because no coronae could be observed. Investigators who have successfully applied the corona method have usually worked in clouds where it is probable that drops of a highly uniform size were encountered.

\section{Conclusion}

The method of measurement of fog particle size described in this paper is now believed to be entirely reliable, and the instruments which have been developed make the application of the method convenient and simple. It now appears that the addition of simple accessory apparatus will enable determination of the number of fog drops in a unit volume of foggy air, as well as their size.

It is hoped that it will be possible to obtain a much greater amount of data in the future in fogs at other locations, as well as in clouds, so that more definite conclusions can be drawn than have been possible on the basis of the relatively small amount of data presented here.

In conclusion the authors wish to express their gratitude for the unfailing support, encouragement and assistance of Professor E. L. Bowles, the Director of the Round Hill Research Division. Much credit is also due the Fog Research mechanician, Mr. Thomas Tedesco, who is responsible for many of the mechanical features of the experimental apparatus described.

\section{REFERENCES}

I. Houghton, H. G. and Radford, W. H., Papers in Physical Oceanography and Meteorology, Massachusetts Institute of Technology and Woods Hole Oceanographic Institution, Vol. VI, No. 3, October I938

2. Houghton, H. G., Physics, 2, 467 (I932)

3. Köhler, H., Met. Zeits., 38, 359 (1921): 40, 257 (1923): 46, 409 (1929) Meddelanden fran Stratens Meteorologisk-Hydrografiska Anstalt, 2, No. 5 (1925)

4. Barus, C., Am. Jl. Sci., 175, 224 (I908)

5. Wagner, A., Sitzb. Akad. Wiss. Wien, I I 7, I281 (1908)

6. Mecke, R., Ann. d. Phys., 61, 471 (1920): 62, 623 (1921)

7. Werner, O., Ann. d. Phys., 70, 375 (1923)

8. Hartmann, W., Das Wetter, I 29 (1924)

9. Richardson, L. F., Quart. Jl. Roy. Met. Soc., 51, I (1925)

10. Wilson, J. G., Camb. Phil. Soc. Proc., 32, 493 (I936)

II. Fuchs, N. and Petrianow, I., Kolloid Zeits., 65, I7I (I933)

12. Heubner, W., Zeits. f. Techn. Phys., 6, I49 (1925)

I3. Rohmann, H., Zeits. f. Phys., I7, 253 (I923)

T.. Findeisen, W., Gerlands Beitr. z. Geophys., 35, 295 (1932)

15. Köhler, H., Met. Zeits., 46, 409 (I929)

I5. Haüsser, F. and Strobl, G., Z. Techn. Phys., 4 (I 924 )

17. Kinoshita, M. and Uchiyama, K., Tokyo U. Inst. Phys. and Chem. Sci. paper No. 391 (1932)

I 8. Hagemann, V., Gerlands Beitr. z. Geophys., 46, 26I (1936)

19. Fuchs, N., Phys. Zeits. Sowjet Union, 10, 3,421 (1936)

20. Fuchs, N. and Petrjanoff, J., Nature, I39 (Jan. I6, I937)

2I. As summarized by Humphreys, "Physics of the Air" (2nd ed.) Ch. VI. 


\section{AN INSTRUMENT FOR SAMPLING AND MEASURING LIQUID FOG WATER*}

BY

W. H. RADFORD

Round Hill Research Division, Department of Electrical Engineering Massachusetts_Institute_of Technology

In connection with a study of the scattering of light by fog, and the development of a method for the local dissipation of fog, it was essential to devise instruments for measuring various fog characteristics. This paper is concerned with one of these instruments -a device which measures the liquid water content of natural fog and which, at the same time, collects samples of the fog water suitable for chemical analysis. Before proceeding with a description of this new apparatus it is in order first to indicate briefly the usefulness of fog water data, and to describe the methods which have been used by various observers to procure them.

Information on the chemical nature of fog water is important in determining the applicability of those fog dissipation methods which eliminate the fog particles by evaporation. Such information is also of considerable meteorological interest because it indicates the chemical nature, and probable source, of the condensation nuclei upon which the fog formed. Knowledge of the liquid water content of fog is likewise important in the application of evaporation methods of fog dissipation since the power required to maintain a clearing of specified size is a function of the amount of liquid water contained in the fog particles. $t$ When liquid water and fog particle size measurements are made simultaneously, it is possible to compute the number concentration of the drops, a quantity of prime interest and importance in the study of problems concerning light transmission and visibility in fog.

\section{Review of Available Methods}

The idea of collecting samples of fog water for chemical analysis is not new. Results of numerous determinations of the chloride content of fog water have been published by Köhler, ${ }^{2}$ who obtained his samples by melting rime. + The routine fog measurements made at Round Hill during the past eight years have included the collection and chemical analysis of samples of fog water. Until recently, these samples were obtained by collecting. fog water on a clean wire screen (preferably nickel) mounted vertically in the fog and

\footnotetext{
* The author was enabled to undertake this work initially through a grant from Mr. Godfrey L. Cabot. Although the research was begun as a part of a light scattering investigation it was continued also as a phase of the Fog Dissipation project supported in part by a grant from the Penrose Fund of the American Philosophical Society and through joint contracts with the Bureau of Aeronautics, U. S. Navy; U. S. Army Air Corps; Bureau of Air Commerce, Department of Air Commerce, covering several years.

The work was carried out at the Institute laboratories on the Round Hill Estate of the late Colonel E. H. R. Green whose foresight and generosity made the project possible. Not only did Colonel Green offer the natural facilities of his estate to the Institute for use as a laboratory but he also aided by numerous gifts, financial and otherwise. Through the courtesy of Mrs. H. Sylvia A. H. G. Wilks, sister of Colonel Green, we have been enabled to continue work at Round Hill so as to complete our projects.

Round Hill is at South Dartmouth, Massachusetts, on the west shore of Buzzards Bay, about six miles south of the city of New Bedford.

T The importance of liquid water content in fog dissipation is brought out by the discussion in reference No. I.

$\ddagger$ "Fog frost" formed by deposition of undercooled fog particles.
} 
faced into the wind.* A trough at the bottom of the screen drains the collected fog water into a clean bottle. A photograph of one of the collecting screens which has been used at Round Hill appears in Fig. I. In order to collect an adequate fog water sample (500 cc or more) within a reasonable time interval it is necessary that the area of the screen be from one and a half to two square meters, and that the fog be accompanied by a wind velocity of at least two and a half meters per second. The principal advantage of this type of fog water collector is its inherent simplicity. Its chief disadvantage is its ineffectiveness in fogs accompanied by little or no wind.

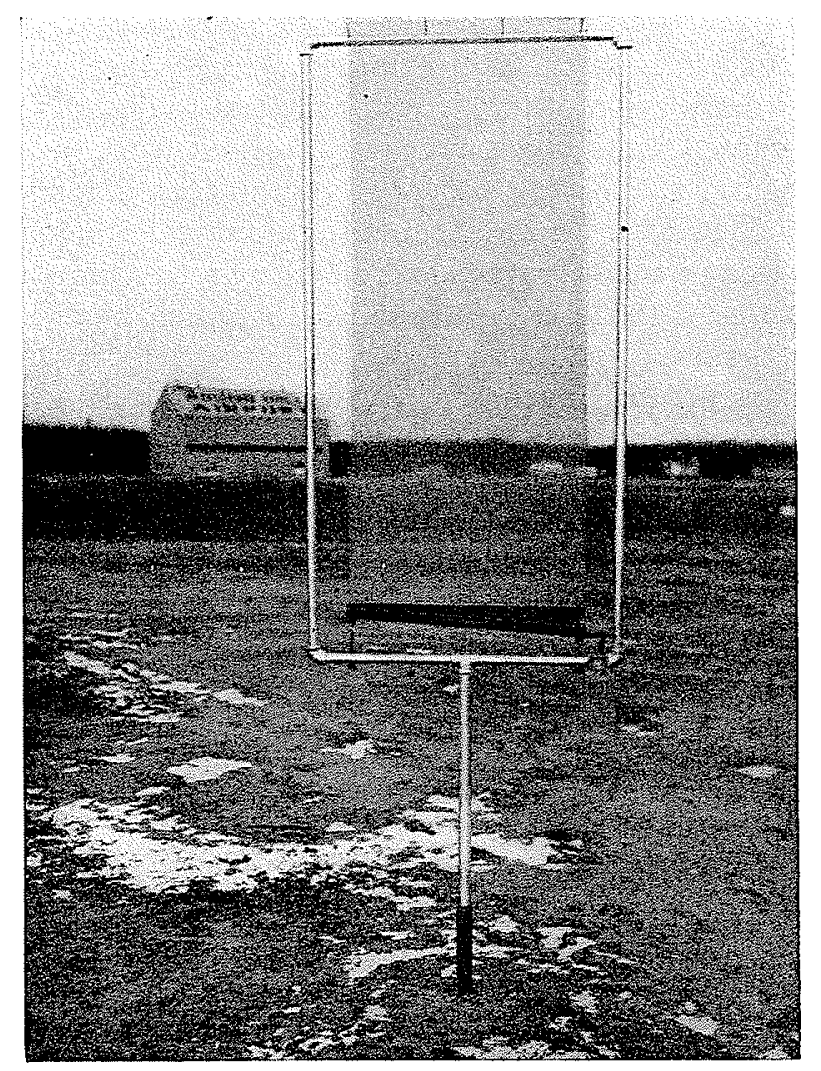

Fig. I.-Single screen fog water collector of the type formerly used at Round Hill. This collector is useful only in fogs accompanied by wind velocities of at least two and a half meters per second. The screen and trough are of nickel; the framework of galvanized iron pipe.

Measurements of the liquid water content of fog have been made by various observers. The more practical methods which have been used are of three general types. One of these is the total absorption method in which the combined amounts of liquid and vapor water are determined by passing a known volume of fog-laden air through an appropriate absorption tube. The relative humidity is assumed or measured, and the liquid water content is obtained by subtracting the corresponding weight of water vapor from the total weight of water removed. Although simple in theory this method is inconven-

* This screen method of fog water collection was suggested by Dr. H. C. Willett of the M.I.T. Meteorological Division who used the method successfully at Nantucket Island a number of years ago. 
ient, tedious, and of limited accuracy. Nevertheless it has been used by numerous observers, notably Conrad ${ }^{3}$ and Wagner. ${ }^{4}$

There are several variations of the evaporation method, in all of which the liquid water determination involves complete evaporation of the fog droplets. Among these are the heated psychrometer of Köhler, ${ }^{5}$ and the heated hygrometer method used by Albrecht. ${ }^{6}$ In both of these methods the combined amounts of liquid and vapor water are determined from relative humidity measurements made in a sample of foggy air which has been heated to produce complete evaporation of the fog particles. As in the absorption method, the relative humidity in the fog is assumed or measured, and the amount of liquid water is determined by subtracting the weight of water vapor from the indicated total. In all methods involving this procedure inaccuracies are probable because of the relatively small amount of liquid water usually present. Frequently in fog the liquid water is only a few per cent of the total water present.

Another evaporation method is that of the fog calorimeter, which directly determines the liquid water content by measuring the heat required to completely evaporate the fog particles. This method was developed at Round Hill several years ago, but has not been used extensively owing to sampling difficulties. The outstanding advantage of the calorimetric and other evaporation methods is that they can be made to yield practically instantaneous and continuous indications of liquid water content.

Finally there are the separation methods, all of which involve the collection and measurement of the water comprising the fog particles in a known volume of foggy air. Among these are the methods of centrifugal separating devices, and of filters or eliminators of one type or another, either mechanical or electrical. The fog water instrument to be described here is of the "separator" type, utilizing a succession of ordinary wire screens as the collecting medium, the idea being essentially an extension of that of the single screen fog water collector previously mentioned. The separation methods of liquid water determination, in general, require only relatively simple apparatus. They are direct and, it will be shown, accurate, and are inherently less susceptible to the sampling difficulties which frequently prevent the successful application of other methods.

\section{The Sampling Problem}

Before proceeding with a description of the new fog water apparatus a brief discussion of the fog sampling problem is in order. It is obviously quite important that any fog measuring instrument operate upon a representative sample of foggy air. The typical sampling problem of most liquid water measuring instruments is essentially that of causing a true sample of fog-laden air to flow into a tube. The nature of the fog sample obtained should be entirely independent of wind or other conditions.

Because of the fundamental importance of the sampling problem considerable attention has been given to it at Round Hill. Numerous tests have been made with small "fog separators" operating under various conditions in both natural and artificial fogs. Samples of fog particles collected on greased glass slides exposed in free air, and also in pipes into which foggy air was being drawn under different conditions, have been studied microscopically. The character of the flow of air into open tubes has also been investigated with the aid of smoke. The results of all of these observations definitely indicate that, except under very favorable conditions, it is practically impossible to cause foggy air to flow into a tube without some loss of liquid water. Usually the character of the airflow at the entrance is such that a substantial proportion of the fog droplets are deposited on the 
tube wall. The special conditions under which this undesirable effect becomes negligible obtain only when the fog is accompanied by a steady wind and the sampling tube is faced directly into the wind, with the velocity into the tube equalling the wind velocity. That is, with a plain open-ended tube, a true sample is procured only when conditions are such that the direction and speed of the air are substantially unchanged upon entering.

The magnitude of error caused by improper sampling depends on the circumstances. Tests made with small fog separators indicate that the error may be only a few per cent when the sampling occurs in still air, or as much as several hundred per cent when the sampling occurs under the most unfavorable conditions. These unfavorable conditions appear to exist, for example, when the sampling tube faces cross-wind and the entrance velocity is at the same time small compared to the wind velocity. The proportion of fog water lost through entrance turbulence depends on the size of the tube, and also on the size of the fog particles, tending to be greater for smaller tubes and larger droplets. In view of the unpredictable nature of the error, it is obviously best to perform the sampling, so far as possible, under the known conditions which eliminate the difficulty.

As a result of the sampling problem investigation, it appeared that one practical and rather obvious solution consisted in the use of a "guard ring" in the form of a much larger tube mounted coaxially with the one in which the true sample of fog-laden air is required. The same velocity is maintained in both tubes. By making the outer tube large compared with the central one, a representative sample of foggy air will enter the latter practically irrespective of wind conditions. The required relative sizes of the guard and measuring tubes depend, of course, on the severity of the worst wind conditions to be encountered. In any case, however, the proportions of the device should be such that all of the air entering the central tube does so without previously having flowed into contact with any other part of the apparatus. The performance of a given unit in this respect may be conveniently observed with the aid of a small smoke source.

The fog water instrument now to be described incorporates the guard tube arrangement described above. By virtue of this feature it appears to be practically exempt from sampling difficulties. Although the fog sampling problem has been recognized previously - notably by Conrad ${ }^{3}$ - it is believed that many of the fog water measuring instruments used in the past have not been properly designed, or have not been so operated as to eliminate the possibility of errors from faulty sampling.

\section{Description of the New Instrument}

As previously indicated, the collection of fog water is accomplished merely by passing a measured volume of foggy air through a succession of ordinary wire screens. The area of the screens and the flow velocity through the instrument are such that a relatively large sample of fog water is obtained in a short time -irrespective of the wind conditions. The apparatus not only collects water samples for chemical analysis, but it also measures the liquid water content of the fog.

The first model of the instrument was constructed at Round Hill in February, I936. Subsequent development has carried it through several stages. The present form of the instrument has been in use about a year and a half. Numerous tests and observations made with it during that time, in both natural and artificial fog, under widely varying conditions, have definitely proven its outstanding superiority as a device for the collection and measurement of liquid fog water. 
The construction of the instrument is evident from the photographs Figs. $2 \mathrm{a}$ and $2 \mathrm{~b}$. The device comprises a plain cylindrical sheet metal tube $6 \mathrm{I} \mathrm{cm}$ in diameter and $92 \mathrm{~cm}$ long. This tube is supported horizontally on a light wooden framework about a meter high. A plate type fan mounted at the discharge end is belt-connected to a $\frac{1}{2}$ hp electric motor. The detachable screen unit is at the intake end. This unit is the essential part of the instrument. It is constructed entirely of stainless steel, and comprises seven screens (18-0.009 inch wires per inch), spaced $0.95 \mathrm{~cm}$ apart and mounted in a short $(20 \mathrm{~cm})$ length of pipe $6 \mathrm{I} \mathrm{cm}$ in diameter. The central portion of this large circular screen unit is

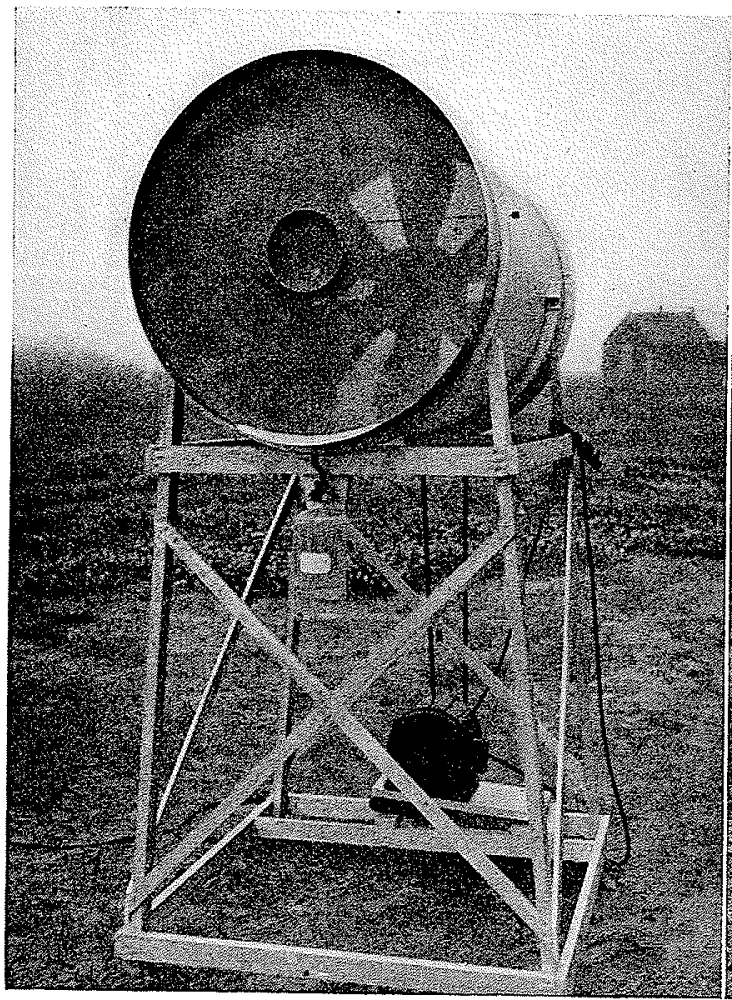

FIG. 2a.-The new fog water sampling and measuring instrument. The small central section of the screen unit, used for liquid water determinations, is removab!e. The annular section of the unit serves as a guard tube for the measuring unit and also as the fog water sample collector.

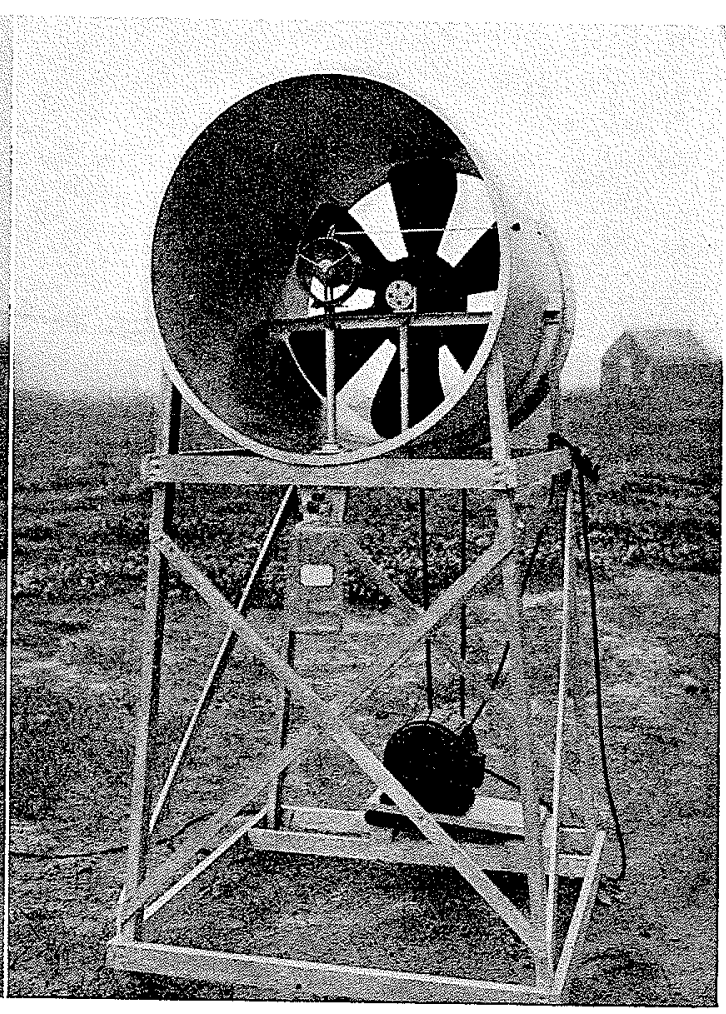

Frg. 2b.-The fog water instrument with the screen unit removed showing the vane anemometer and fan. The small rod extending from the top of theanemometer through the side of the large pipe controls the anemometer recording dials, which indicate feet of air.

cut away to permit the coaxial mounting of a short sheet metal tube $12.7 \mathrm{~cm}$ in diameter. Fitting snugly within this tube is a second removable unit, comprising seven wire screens of the same type and having the same spacing as those in the outer section. This central unit, which has a dry weight of only 73 grams, is used in making the liquid water determinations. The outer annular portion of the screen unit serves as a guard tube for the central measuring unit, and also as the collector of samples of fog water for chemical analysis. The fog water accumulating on the annular screens drains to a sump at the bottom of the unit, and thence in to the sample bottle. A calibrated vane anemometer is mounted directly in back of the central removable unit and serves for measuring the 
air velocity. The location of this anemometer is apparent from Fig. 2b, which is a view of the fog water instrument with the screen unit removed. The vane anemometer is equipped with dials which can be conveniently read from the fan end of the large tube.

Two important accessories of the fog water instrument are shown in Figs. 3 and 4 . Fig. 3 is a photograph of the stainless steel container in which the screen unit is washed,

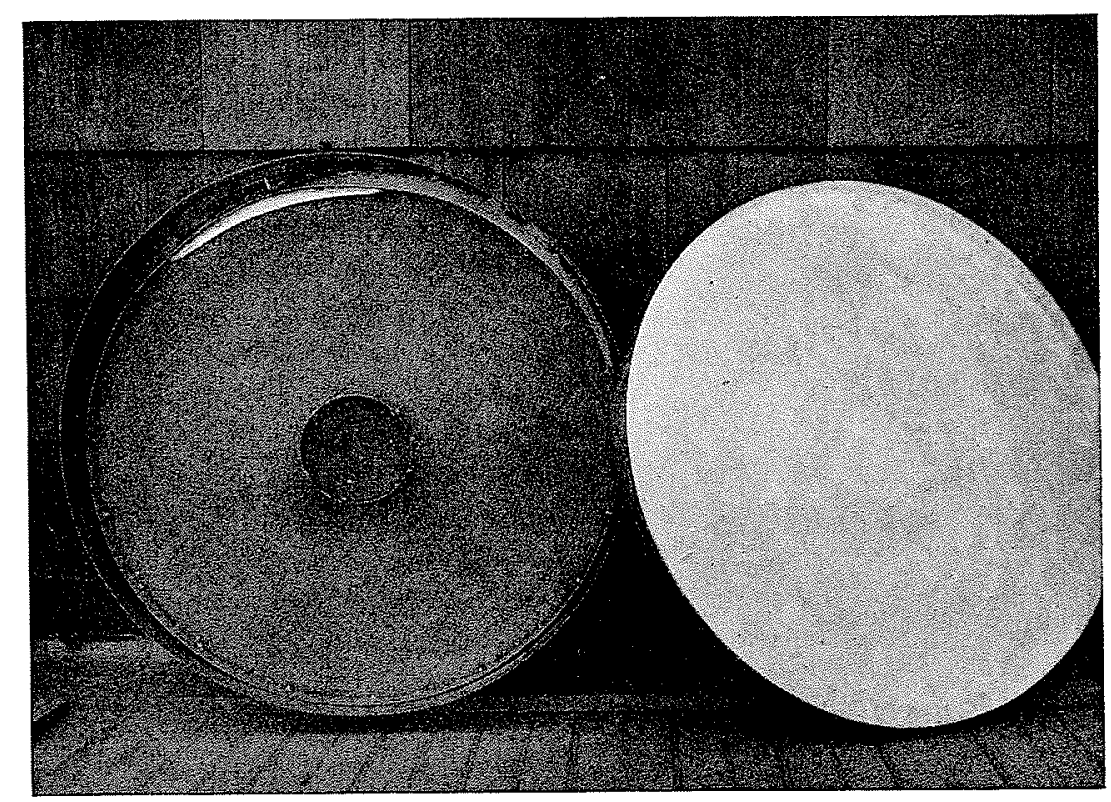

FIG. 3.-Photograph of the fog water collector screen in its stainless steel storage container. The container is about $23 \mathrm{~cm}$ deep and $66 \mathrm{~cm}$ in diameter

and in which it is stored when not in use. Fig. 4 is a photograph of the small balance used for weighing the central measuring portion of the screen unit. This balance is of the conventional triple beam type and has a sensitivity of $0.0 \mathrm{I}$ gram. It is mounted in a specially constructed case to protect it from the weather.

\section{Discussion of Operating Conditions}

The fog water apparatus is usually operated with the screen unit faced directly into the wind. The liquid water determinations are made by measuring the weight increment of the small central screen unit in a convenient time interval. The average air velocity over the same period is indicated by the anemometer. These data, together with the known values of the sectional area of the screen unit $\left(126.5 \mathrm{~cm}^{2}\right)$ and the separation efficiency (approximately 90\%), enable direct computation of the liquid water content of the fog. The length of the test interval is governed chiefly by the fog density and is usually from one to ten minutes. The interval should never be so long that the quantity of fog water accumulated by the measuring unit is greater than can be safely retained. This limiting quantity for the apparatus described is about 8 or io grams. The accumulation of an undue amount of water is prevented by shaking the excess from the unit after making the final weighing of each test. The balance (Fig. 4) is usually 
located near the fog water apparatus, right out in the fog to eliminate the possibility of loss of water through evaporation while the weighings are being made.

The normal air velocity through the fog water instrument is about 6 meters per second. When the instrument operates in fog having a liquid water content of only 0.1 gram per cubic meter, the annular portion of the screen unit collects fog water at the rate of approximately 9 grams per minute, while the smaller measuring unit accumulates about $0.4 \mathrm{I}$ gram per minute. Thus in half an hour a large enough sample is obtained for chemical analysis. In such fog a convenient test interval for liquid water determinations
is from 4 to Io minutes.

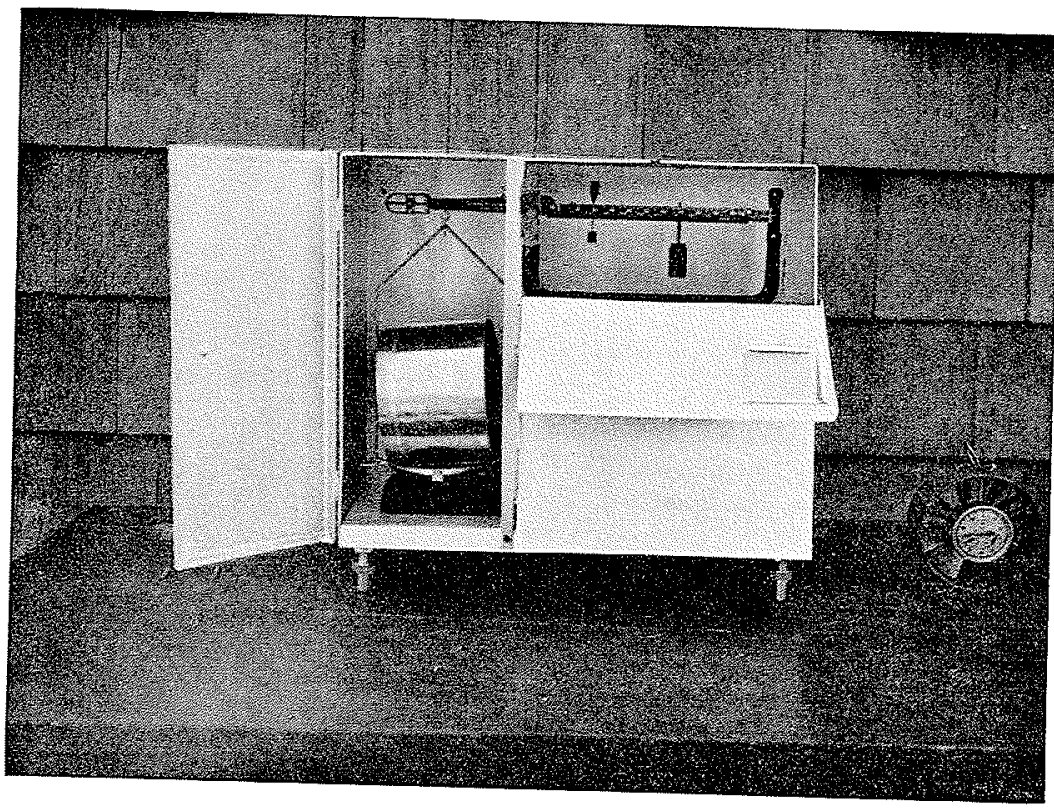

Fig. 4.-The triple-beam balance used for weighing the small screen-unit. The unit reposes on the balance pan. The sheet metal case completely shields the balance from the weather and permits weighings to be made right out in the fog. The vane ane-

The fog water collection rate of the instrument could be somewhat improved by increasing the air velocity. There are, however, two practical considerations which should be noted. For one thing the power required to drive the fan increases approximately as the cube of the air velocity. A $\frac{1}{2}$ hp motor is required to operate the instrument satisfactorily with an air velocity of 6 meters per second. To increase this velocity only $50 \%$ would require a motor of a size almost prohibitive in a portable instrument. Another serious objection to appreciably increasing the flow through the present apparatus is that as the linear velocity is raised beyond 9 meters per second the collection
efficiency of the screen unit rapidly diminishes.

The collection efficiency of the screen unit of the fog water apparatus has been the subject of considerable experimental investigation in both natural and artificial fogs. One would expect that the efficiency would be a function of the size of the particles, the air velocity, and the degree of wetting of the wire screens. It was found that for particles 


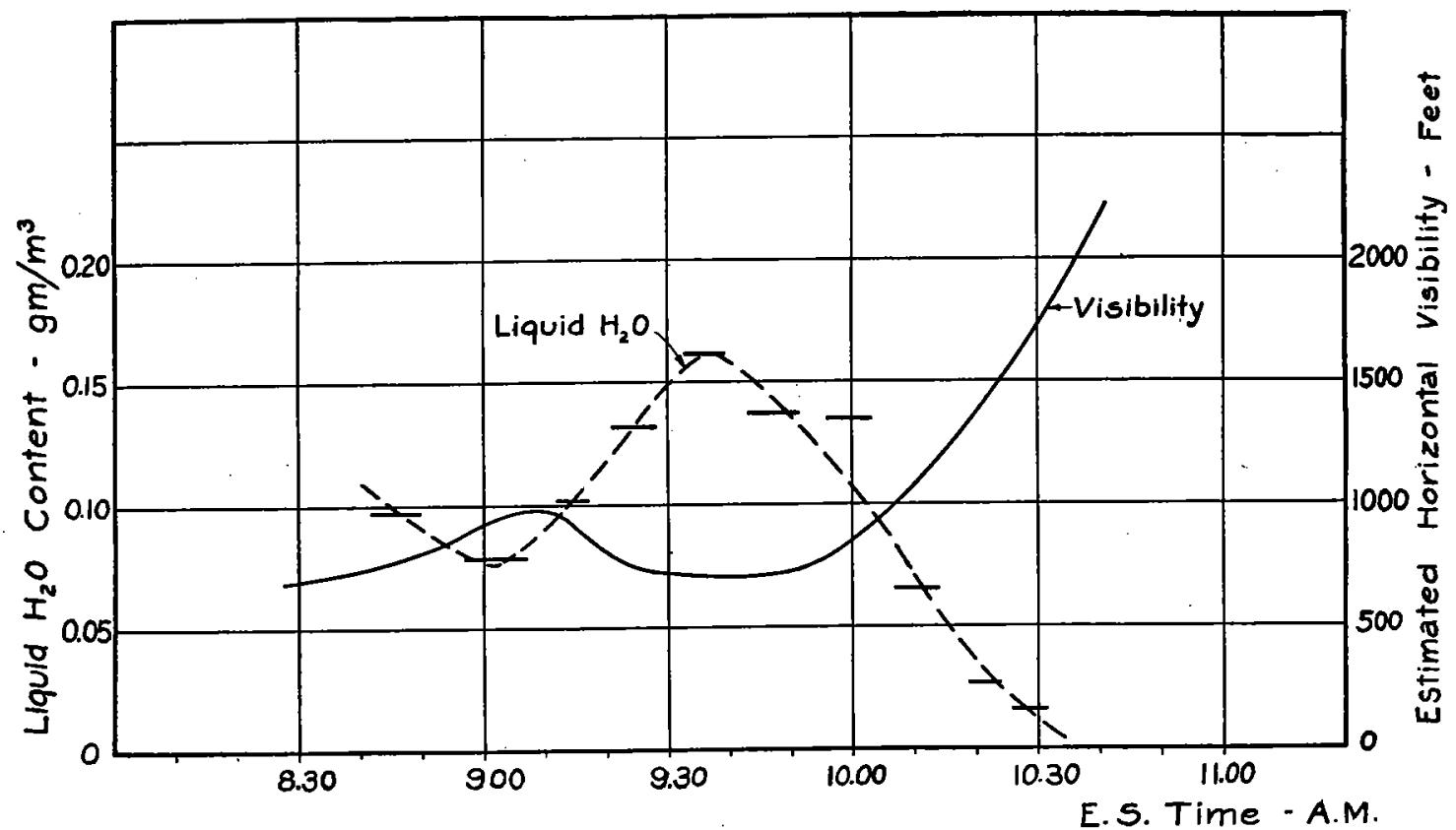

FIG. 5- - Results of liquid water determinations in fog at Round Hill on Sept. 24, 1936. Wind direction NE, velocity $2 \mathrm{~m} / \mathrm{sec}$, barometer $760 \mathrm{~mm}$, tempera ture $17.5^{\circ} \mathrm{C}$. The values of liquid water content are indicated by the horizontal dashes, the length of each dash indicating the duration of the test interval.

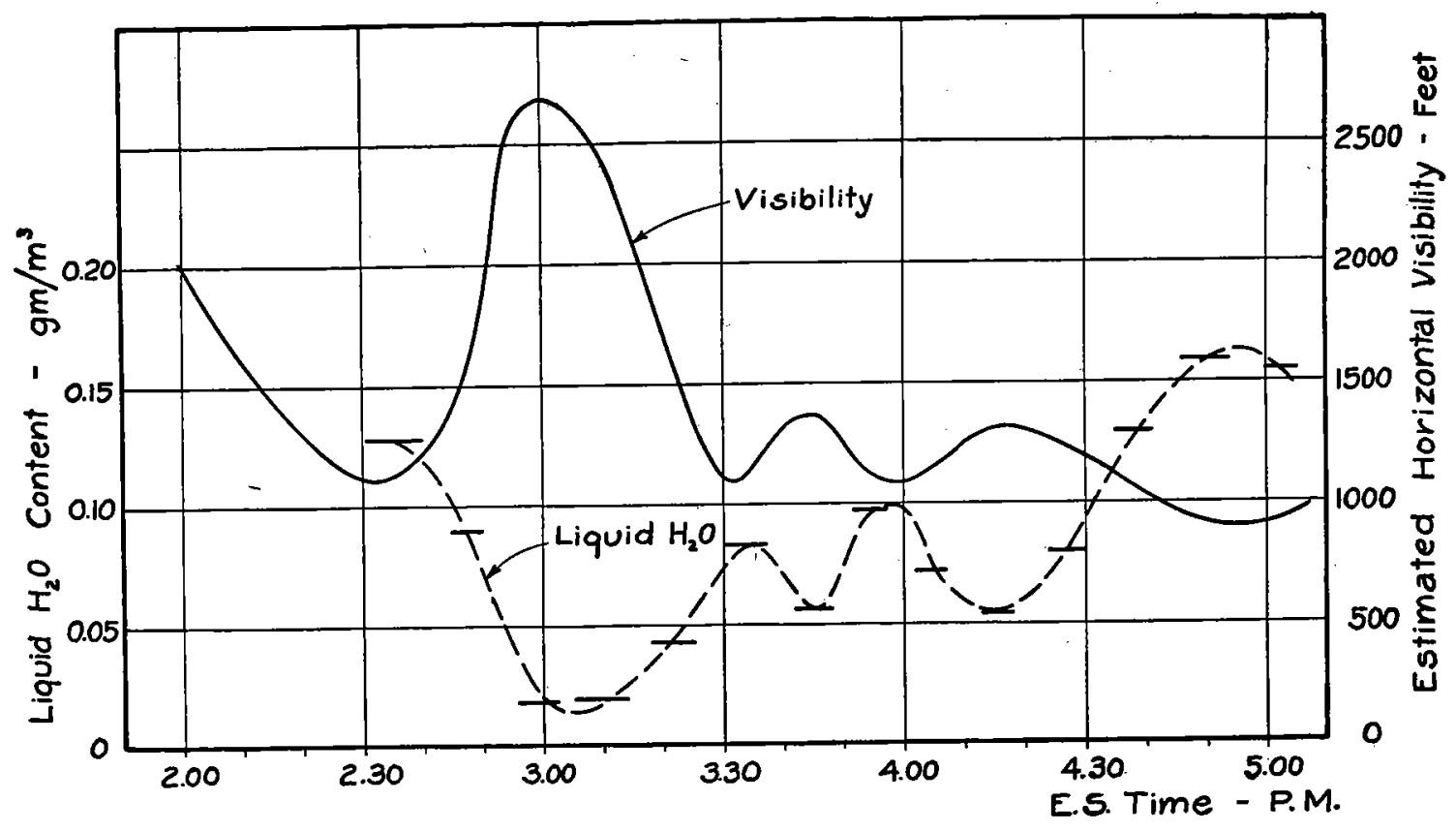

FIG. 6.-Results of liquid water determinations in fog at Round Hill on Oct. 10, 1936. Wind direction SW, velocity $6.7 \mathrm{~m} / \mathrm{sec}$, barometer $760 \mathrm{~mm}$, temperature $17.2-17.5^{\circ} \mathrm{C}$. 


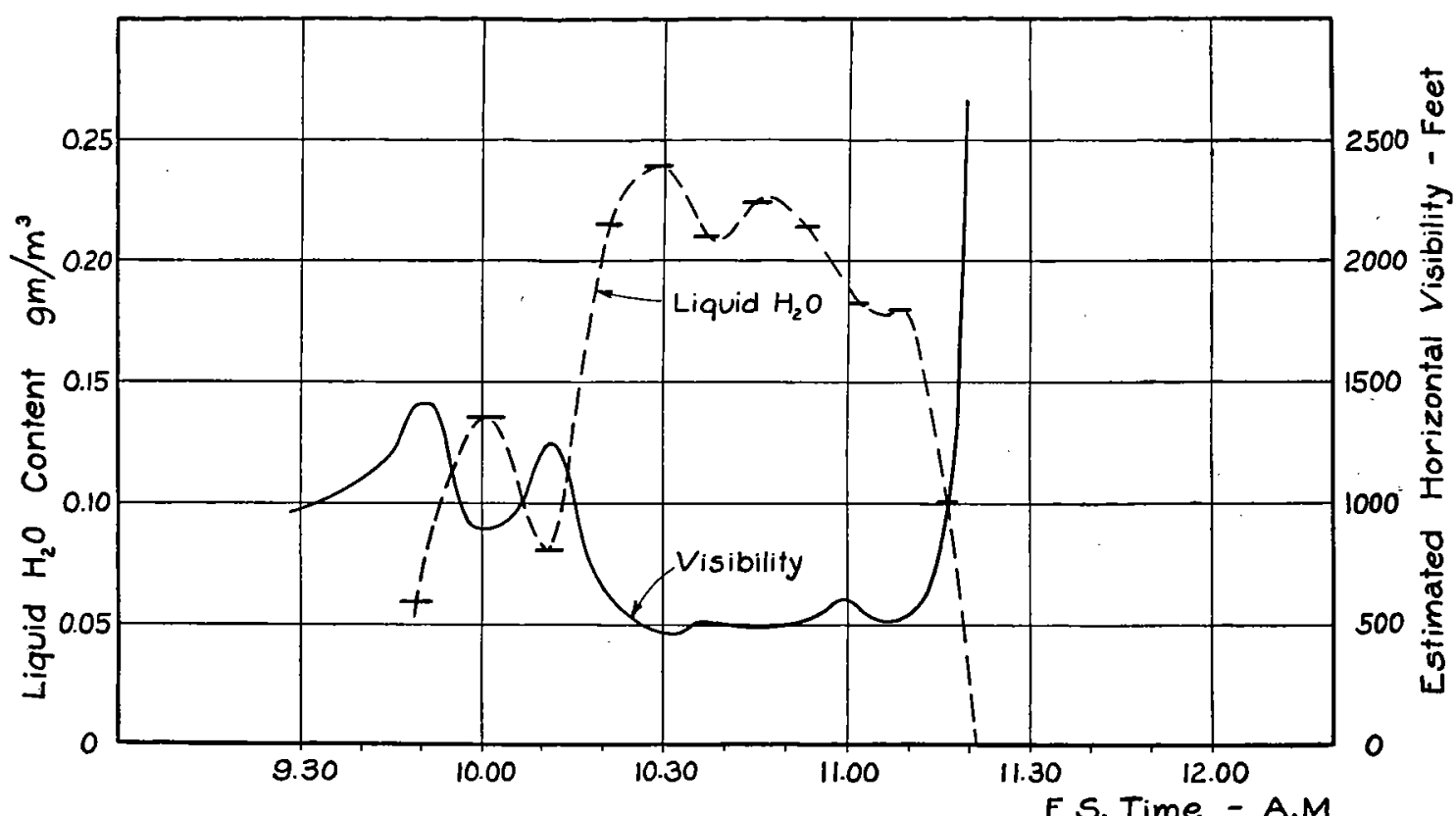

FIc. 7.-Results of liquid water determinations in fog at Round Hill on Dec. I1, 1936. Wind direction S, velocity $1.3 \mathrm{~m} / \mathrm{sec}$, barometer $765 \mathrm{~mm}$, temperature $4.7-5.4^{\circ} \mathrm{C}$. Abrupt clearing of fog at I I.20 a.m. accompanied by shift of wind direction to $W$ and an increase in air temperature.

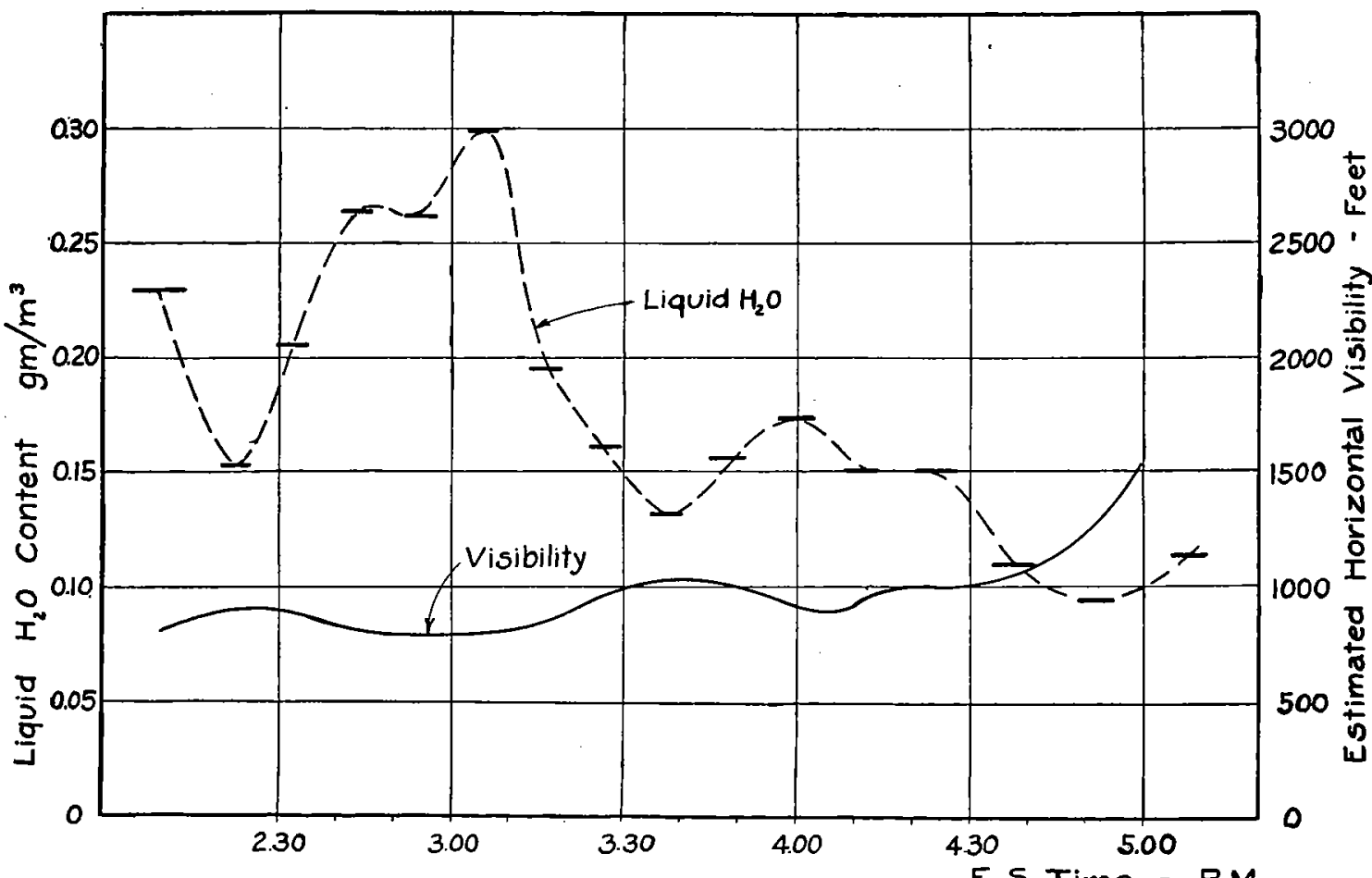

E.S. Time - P.M.

Frg. 8.-Results of liquid water determinations in fog at Round Hill on Jan. I4, I937. Wind direction SW, velocity $7.2 \mathrm{~m} / \mathrm{sec}$, barometer $764 \mathrm{~mm}$, temperature $7.1-7.5^{\circ} \mathrm{C}$. Apparent increase in visibility around $4.40 \mathrm{p} . \mathrm{m}$. due to nightfall, after which estimates of visibility were made with markers consisting of lights at known distances. 
having size distributions of the sort likely to be encountered in natural fog (diameters between 2 and I00 microns) the collection efficiency of the screen unit lies between 87 and $94 \%$ for air velocities under 9 meters per second. The change in efficiency with the degree of wetting of the screens may be neglected. In view of the small variation in efficiency, and the possibility of larger errors from other sources, it is sufficiently accurate for the present to assume that in natural fog the collection efficiency of the screen unit is about $90 \%$ for all velocities under 9 meters per second. As the velocity is raised to higher values the efficiency decreases due to the tearing off from the screens of large drops of collected water.

The static pressure drop through the screen unit of the present apparatus (including the entrance loss) is small, being about $0.74 \mathrm{~cm}$ of water at the normal flow velocity of 6 meters per second when the screen unit is dry, and only $70 \%$ greater when the screens are dripping wet. Such a small pressure change is insufficient to cause appreciable expansional cooling of the air passing through the unit, so there is no possibility of error from that effect.

One likely source of error in liquid water determinations is in the measurement of air flow. However, the anemometer used for this purpose has been calibrated under the actual conditions of use, by direct comparison with a pitot tube, so the flow measurements are probably reliable within $5 \%$. Other possible causes of erroneous liquid water indications are changes in air temperature or relative humidity during a test interval. Usually, though, these quantities are substantially constant under stable fog conditions. An actual determination of the accuracy of liquid water measurements made with the new instrument has not been possible owing to the lack of a standardized fog. However, it appears from a consideration of the various sources of error that the indications of the instrument should usually be within $10 \%$ of the correct value.

The fog water apparatus described has one important limitation which should be noted. It cannot be used under freezing conditions because the wire screens soon become plugged with rime. However, this difficulty could doubtless be obviated by equipping the instrument with a collector unit comprising elements of such open construction that they would not be obstructed by moderate accumulations of rime. Such a collector could be constructed by using a large number of screens of very coarse mesh, or by using a succession of rows of streamlined tubes or bars. * Several such collecting and measuring units could be provided, and when one accumulated an excessive amount of rime it could be replaced by a fresh unit and removed to a warm place where the rime could be melted off and the resultant fog water saved for chemical analysis.

\section{Results of Liquid Water Measurements in Fog}

Typical data on the liquid water content of natural fog obtained with one of the new instruments are presented in Figs. 5, 6, 7, and 8. These curves show the variations of both liquid water content and horizontal visibility with time in four different fogs. In each case it is interesting to note the correlation between liquid water content and visibility. It will be noticed, however, that the estimated horizontal visibility is not always the same in different fogs having the same liquid water content. This is due to the dependence of visibility upon other factors, notably the size of the fog particles.

Although estimates of horizontal visibility are at best a very poor measure of fog

* Collector units of this general type have been used successfully in experimental fog dissipation equipment at Round Hill. See reference No. I. 
density they are, nevertheless, frequently useful in indicating changes in density under a particular set of fog conditions. With proper care, visibility estimates can also be used to indicate the order of magnitude of liquid water content. Fig. 9, which has been prepared with data from the various sources noted, shows measured values of liquid water content versus estimated values of horizontal visibility.

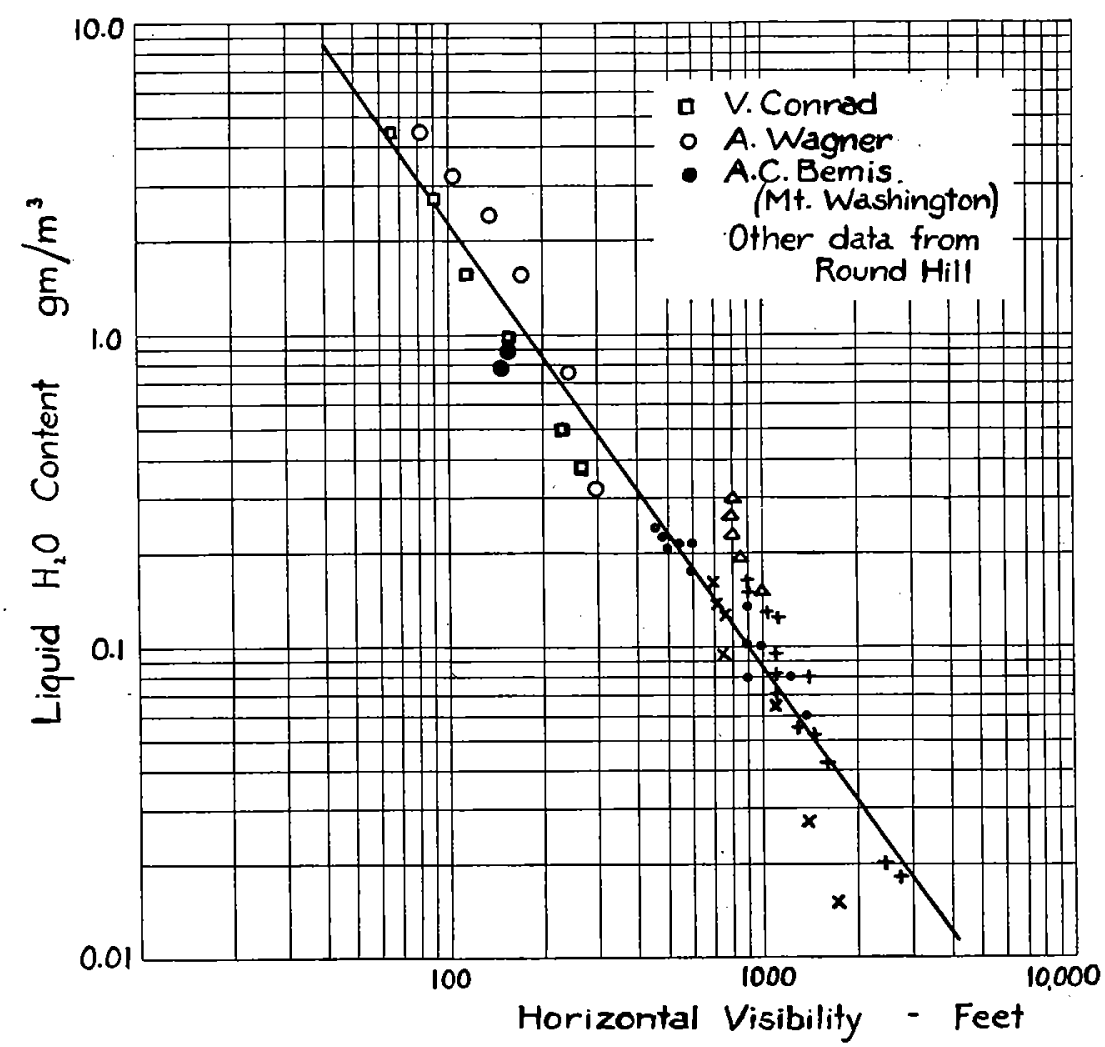

F1G. 9.-Data from several sources showing measured values of liquid water content in fogs and clouds versus estimated values of horizontal visibility. Scattering of the points is owing to the dependence of visibility on factors other than liquid water content-notably drop size.

On an occasion when the fog was accompanied by a $6.7 \mathrm{~m} / \mathrm{sec}$ ( $5 \mathrm{mph}$ ) wind, a series of simultaneous observations were made with two of the new fog water instruments in order to determine the effects of operating one instrument facing cross-wind and in to the wind at both normal $(6 \mathrm{~m} / \mathrm{sec})$ and very low $(1.5 \mathrm{~m} / \mathrm{sec})$ air velocities. Except for the condition of cross-wind operation at low velocity, the indications of the two instruments were always in good agreement. This fact, together with the results of observations of smoke flowing into the screen unit under various wind conditions, definitely establishes the effectiveness of the guard tube in eliminating sampling difficulties.

Several times when liquid water measurements were being made, simultaneous observations were made with a fog microscope* in order to determine the size distribution of the fog particles. Knowing both the liquid water content and the size distribution it was easily possible to compute the actual number of fog particles in a unit volume of

* See Part I. 
foggy air. The observations upon which these computations are based and the results appear in Table I. With one exception the number of particles per cubic centimeter was always less than five.

TABLE I

Fog Data Obtained at Round Hill.

\begin{tabular}{|c|c|c|c|c|c|c|c|c|c|c|}
\hline \multirow{2}{*}{ Date } & \multirow{2}{*}{ Time } & \multirow{2}{*}{$\begin{array}{c}\text { Estimated } \\
\text { Visibility } \\
\text { Feet }\end{array}$} & \multirow{2}{*}{$\begin{array}{c}\text { Air } \\
\text { Temp. } \\
{ }^{\circ} \mathrm{C}\end{array}$} & \multicolumn{2}{|c|}{ Wind } & \multicolumn{3}{|c|}{ Drop Diameters $\mu$} & \multirow{2}{*}{$\begin{array}{l}\text { Liquid } \\
\text { Water } \\
\mathrm{g} / \mathrm{m}^{3}\end{array}$} & \multirow{2}{*}{$\begin{array}{l}\text { Number* } \\
\text { of drops } \\
\text { per cc }\end{array}$} \\
\hline & & & & Dir. & $\mathrm{m} / \mathrm{sec}$. & Min. & $\begin{array}{l}\text { Predom- } \\
\text { inant }\end{array}$ & Max. & & \\
\hline 361010 & 5.00 p.m. & 900 & 17.4 & SW & $5 \cdot 4$ & 4 & 40 & 88 & 0.155 & $3 \cdot 75$ \\
\hline 361211 & 10.00 a.m. & I 200 & 4.8 & $\mathbf{S}$ & I. 3 & 4 & 36 & 130 & 0.135 & 1.36 \\
\hline & $10.20 \mathrm{a.m}$. & 500 & 5.1 & $S$ & I. 3 & 4 & 54 & 120 & 0.200 & I. 50 \\
\hline “ & ro. 35 a.m. & 450 & 5.1 & S & I. 3 & 4 & 32 & 88 & 0.222 & 5.97 \\
\hline $3701 I_{4}$ & 3.34 p.m. & 1000 & $7 \cdot 5$ & SW & 6.7 & I & 42 & 100 & 0.139 & 2.22 \\
\hline 《 & 4.07 p.m. & I000 & $7 \cdot 4$ & SW & 6.7 & I & 39 & 100 & $0.16 I$ & 2.89 \\
\hline$"$ & 4.25 p.m. & 1000 & 7.1 & SW & 7.6 & 3 & 43 & 90 & 0.150 & 3.14 \\
\hline « & $4.5 \mathrm{I}$ p.m. & 1200 & 7.2 & SW & 7.6 & I & 34 & 105 & 0.095 & 1.92 \\
\hline “ & 5.09 p.m. & - & 7.2 & SW & 8.0 & I & $4 \mathrm{I}$ & 100 & 0.117 & 2.16 \\
\hline & 5.26 p.m. & & 6.9 & SW & 7.2 & I & $4 \mathrm{I}$ & 100 & 0.122 & I.9I \\
\hline
\end{tabular}

* It is probable that the values in this column are somewhat low owing to errors in the fog particle size distribution data. These errors arise from difficulties in collecting representative samples of fog drops on microscope slides. This problem is discussed in Part I of this paper.

\section{Collection of Fog Water Samples for Chemical Analysis}

When the fog water instrument is used for the collection of samples for chemical analysis it is of the utmost importance that the screen unit be kept clean. The salt concentration of fog water is exceedingly low, so the slightest contamination is undesirable. It is customary to clean the screen unit, when necessary, by washing it first in carbon tetrachloride and then in hot distilled water. The cleaned unit is handled only with clean rubber gloves and except when in use is stored in the metal container provided for the purpose (Fig. 3).

As stated previously, practically all of the fog water samples collected at Round Hill during the past eight years were obtained with the single screen fog water collector, which depends upon the wind for its successful operation (Fig. I). This instrument served satisfactorily because fogs which occur at Round Hill are practically all of the advection type and are invariably accompanied by moderate winds.

Results of chemical analyses of Round Hill fog water samples indicate that the total dissolved salt content ranges from 8 to $480 \mathrm{mg} /$ liter and averages about $70 \mathrm{mg} / \mathrm{liter}$. The principal constituents appear to be chlorides and sulfates. The purposes, methods and results of the analysis of these and other fog water samples will be fully described in a forthcoming paper.

\section{Conclusion}

The results of numerous tests and observations with the new fog water sampling and measuring instrument indicate that it is generally satisfactory. It performs two important measuring operations in fog and is reliable, reasonably accurate, and convenient to use. It is portable and relatively inexpensive. It is operable under all probable surface wind conditions, and appears to be exempt from the sampling difficulties which, at least in the authors' experience, have usually prevented successful performance of other fog 
measuring instruments. One of these new instruments together with a fog microscope* makes possible the determination of the most important physical characteristics of fog. All of these features make the new fog water instrument well suited to the requirements of field use.

Recently a modest program of field observations in fog was undertaken with the generous cooperation of Mr. Alan C. Bemis. Measurements have already been made with a fog water instrument and a fog microscope at several locations, including the summit of Mt. Washington. When additional data have been obtained a complete account of this work will be published.

It appears to be highly desirable to extend the program of field measurements already initiated so as to include regular observation in fogs (or clouds) at other locations. The results of such observations would be useful in determining the applicability of hygroscopic methods of fog dissipation at strategic points. When properly correlated with other factors they would also be of considerable meteorological interest. There seems to be little doubt of the desirability of obtaining more information on the physical characteristics of fogs and clouds generally in order to enable a better understanding of the processes of fog and rain formation.

In conclusion the author wishes to acknowledge his indebtedness to Professor E. L. Bowles, Director of the Round Hill Research Division, without whose wise counsel and unfailing support and encouragement the work described could not have been carried through to its logical conclusion. Much credit is also due Mr. H. G. Houghton who made many helpful suggestions in the course of the development of the fog water instrument, and who also participated actively in conducting the numerous fog measurements. Credit is also due Mr. Thomas Tedesco, the mechanician who constructed the final instrument and most of the experimental apparatus required in its development.

* See Part I.

\section{REFERENCES}

I. H. G. Houghton and W. H. Radford, Papers in Physical Oceanography and Meteorology, Massachusetts Institute of Technology and Woods Hole Oceanographic Institution, Vol. VI, No. 3, October 1938.

2. H. Köhler, Met. Zeits. 38, I68 (I921); Met. Zeits. 39, 263 (1922); Met. Zeits. 46, 409 (I929); Meddelanden Fran Stratens Meteorologisk-Hydrografiska Anstalt, Band 2 No. 5 (I925

3. V. Conrad, Wiener Denkschr. 7, II 5 (I9OI)

4. A. Wagner, Akad. Wiss. Wien. Sitz. Ber. II 7, 2a, 1218 (Dec. I908)

5. H. Köhler, Meddelanden Fran Stratens Meteorologisk-Hydrografiska Anstalt, Band 5, No. 2 (1928)

6. F. Albrecht, Met. Zeits. 42, 468 (I925) 